\title{
Una geografía del terror para la fase final de los años de plomo: las víctimas de las Fuerzas y Cuerpos de Seguridad del Estado en el País Vasco (1982-1994)
}

\section{A map of terror for the last phase of the years of lead: State Security Force victims in the Basque Country (1982-1994)}

David Mota-Zurdo

david.mota@ui1.es @ 0000-0002-9578-8069

Facultad de Humanidades y Ciencias Sociales. Universidad Isabel I.

C/ Fernán González, 76. 09003 Burgos, España.

\section{INFO ARTÍCULO}

Recibido: 08-04-2021

Revisado: 04-05-2021

Aceptado: 08-05-2021

\section{PALABRAS CLAVE}

Terrorismo

Víctimas

Territorio

País Vasco

Democracia

\begin{abstract}
RESUMEN
Este artículo es un análisis cuantitativo de las víctimas, miembros de las Fuerzas y Cuerpos de Seguridad del Estado, que fueron asesinadas por ETA y grupos afines en el País Vasco entre 1982 y 1994. Partiendo de una óptica territorial, se pone un especial énfasis en la procedencia de las víctimas, en su lugar de asesinato y en el cuerpo policial al que pertenecieron, pues la finalidad es elaborar una radiografía del impacto que tuvieron las acciones terroristas contra las Fuerzas y Cuerpos de Seguridad del Estado en Euskadi. Sin hacer un análisis pormenorizado de cada víctima, en esta investigación se estudian y comparan los datos de aquellas que fueron guardias civiles, policías y militares utilizando una metodología descriptiva y un enfoque positivista. El objetivo del artículo, que es comprobar qué cuerpo policial y militar fue el más azotado por la violencia terrorista y subrayar aquellos municipios, comarcas y provincias vascas más mortíferos, se cumple tras concluir que Gipuzkoa fue el principal lugar de fallecimiento de los miembros de FCSE, siendo los castellanoleoneses, y no los andaluces, los más afectados por el terrorismo.
\end{abstract}

\section{KEYWORDS}

Terrorism

Victims

Territory

Basque Country

Democracy

\begin{abstract}
This article is a quantitative analysis of the victims, members of the State Security Forces, who were murdered by ETA and other terrorist groups in the Basque Country between 1982 and 1994. Starting from a territorial perspective, is emphasized on the origin of the victims, in their place of murder and in the police force which they belonged: the purpose is to get a panoramic photo of the impact that the terrorist actions had against the State Security Forces in Euskadi. Without making a detailed analysis of each victim, this research analyzes and compares the data of those who were civil guards, police and military using a descriptive methodology and a positivist approach. The objective of the article, what is to verify which police and military force was the most affected by terrorist violence and to highlight those Basque towns, regions and provinces that were the deadliest, is met after concluding that Gipuzkoa was the main place of death of the members of the Security Forces, being the Castilian-Leonese, and not the Andalusians, the most affected by terrorism.
\end{abstract}




\section{INTRODUCCIÓN}

El 20 de octubre de 2011, la organización terrorista ETA (Euskadi Ta Askatasuna, País Vasco y Libertad) anunció el cese definitivo de su actividad armada. Tras el final de la violencia terrorista, se abrió un nuevo escenario donde la pacificación del País Vasco se convirtió no ya en un objetivo, sino en un fin al alcance de la mano. Pronto, al calor de estos cambios, hubo un notable incremento del número de productos literarios y audiovisuales sobre ETA, sus acciones y sus víctimas. Y con ellos se reavivó un viejo debate, el del relato, que desde entonces ha sumergido a la sociedad civil en una amarga batalla en la que sus diferentes sectores políticos pugnan por imponer una determinada narrativa sobre lo que fue el «conflicto vasco».

El boom de monografías académicas, novelas y producciones cinematográficas que ha experimentado nuestro país ha sido enorme, desde las obras de Fernando Aramburu a series televisivas como La línea invisible, de Mariano Barroso. Todos estos trabajos han contribuido a que la memoria del terrorismo esté en el debate público. Y aunque se ha avanzado mucho, sobre todo si se tiene en cuenta que para octubre de 2011 la producción académica sobre la historia del grupo nacionalista vasco radical era ya ingente, lo cierto es que los claroscuros continúan siendo importantes, sobre todo en un apartado cardinal: las víctimas de las acciones terroristas.

Ha habido un incremento exponencial del número de estudios sobre las víctimas de ETA en las que se ha prestado una atención preferencial a las personas asesinadas, heridas y mutiladas. Sin embargo, todavía hay muchos vacíos que paliar. Este trabajo aspira precisamente a desbrozar una parte de esa laguna historiográfica al centrarse en las víctimas mortales de las Fuerzas y Cuerpos de Seguridad del Estado (FCSE) en el País Vasco entre 1982 y 1994 (etapa de la consolidación democrática) desde una óptica territorial. Dada la finalidad y espacio del estudio, las acotaciones cronológicas y temáticas señaladas eran necesarias porque a lo largo de este periodo, que frisa el final de la transición a la democracia, las FCSE fueron el principal objetivo tanto de ETA militar (ETAm) como de ETA político-militar (ETApm), que colocó a policías, militares y guardias civiles en su diana por considerarles fuerzas invasoras fascistas. Incluso una vez entrada en vigor la Constitución de 1978 y aprobado el Estatuto de Gernika un año después, ETA mantuvo durante este tiempo una actitud de confrontación contra el Gobierno de España y sus cuerpos de seguridad en el País Vasco (De la Calle y Sánchez-Cuenca, 2004: 70).

ETAm (simplemente ETA a lo largo de este artículo), que fue el principal grupo terrorista que atacó a las FCSE tras la disolución de ETApm en 1982, justificó sus acciones aduciendo que estas habían estado implicadas en la represión tardofranquista y en los primeros momentos de la democracia, basando su argumentario en los continuos estados de excepción, la contestación a las protestas obreras derivadas de la reconversión industrial de principios de la década de 1980 o en el frustrado golpe de Estado de Tejero de 1981. Por tanto, según la lógica etarra, el Gobierno de España continuaba siendo el enemigo del pueblo vasco, por lo que su actitud debía continuar siendo la misma que contra el franquismo: combatir a una dictadura militar encubierta, a un país y a un gobierno fascistas que usaban a las FCSE para imponer su voluntad. Esta estrategia no cambió ni con la llegada del socialista Felipe González a La Moncloa en octubre de 1982 (Fernández Soldevilla, 2016, p. 298; Pérez, 2021; Domínguez, 2006, p. 300).

Como han destacado Llera y Leonisio (2017), el discurso de ETA contra las FCSE tuvo su impacto sobre la sociedad vasca. Aunque fuera más por temor que por convicción ideológica (pese a la existencia de un colectivo significativo en número que era próximo a Herri Batasuna, HB: el brazo político de ETA), sus acciones contribuyeron a que en el País Vasco hubiera un notorio distanciamiento entre la sociedad, los militares y los cuerpos policiales que en el corto-medio plazo redundó en la cosificación de la víctima y en el mantra del "algo habrá hecho", que justificó indirectamente las acciones terroristas. Parafraseando a Luis Castells (2017): ante el terrorismo (y las víctimas), la sociedad vasca cerró sus ventanas y se sumergió en el silencio.

Junto a estos factores hubo otro determinante: Ios recelos hacia las FCSE de la clase política, principalmente la oposición y los partidos extraparlamentarios. Esta circunstancia, sumada a la falta de material apropiado y la bisoñez de muchos agentes, así como la carencia de una estrategia policial clara en la lucha contra el terrorismo en los primeros años de la democracia, provocó que la atmósfera para hacer frente a los terroristas no fuera favorable. El resultado fue el siguiente: entre 1983 y 1995 ETA asesinó a más de 200 miembros de los 
diferentes cuerpos policiales y militares, siendo especialmente virulentas sus acciones en el País Vasco, como se verá en las siguientes páginas (Labiano \& Marrodán, 2018, p. 234).

En este artículo se hace un recorrido por los atentados de ETA y grupos terroristas afines, como los Comandos Autónomos Anticapitalistas (CAA), el grupo más mortífero del País Vasco después de ETA (Estebaranz, 2011), contra las FCSE, prestando atención al origen de las víctimas y su lugar de asesinato. Y se analiza un periodo especialmente virulento para éstas en democracia: el comprendido entre 1982 y 1994 . El punto de partida es la premisa de que si se pone el foco en ambas variables se observa con claridad qué cuerpo de las FCSE fue el más azotado por la violencia terrorista y qué territorios (municipio, comarca y provincia) fueron los más mortíferos.

\section{ANTECEDENTES TEÓRICOS}

En los años inmediatamente posteriores al comunicado de ETA de 2011 al que se ha hecho alusión en la introducción, los estudios que se publicaron sobre la organización nacionalista vasca radical se centraron básicamente en analizar las claves de su final desde un punto de vista politológico, periodístico y sociológico, entre otros. Se trató de trabajos de calidad y enfoque diversos, entre los que sobresalieron los siguientes: Batista (2011) Escrivá (2012) y Azurmendi (2012 y 2014); los trabajos de Cid Cebrián (2013) y Rodríguez Aizpeolea (2013), y de este último con Eguiguren (2012) y con Izquierdo (2017); el ensayo de Murua (2016), la obra coordinada por Cuerda (2016) y la monografía de Oneto (2017); los volúmenes sobre la estrategia policial contra ETA de Sánchez Corbí y Simón (2017) y de Silva, Sánchez y Araluce (2017); los trabajos de Domínguez (2017) y Alonso (2018) sobre el final de la organización; o el más reciente estudio sobre el final del terrorismo desde la perspectiva del derecho de Heredero (2020).

En paralelo a estos estudios se fueron publicando análisis de un espectro más amplio, que no se centraron exclusivamente en los años finales de ETA y que analizaron el fenómeno de la violencia terrorista desde su origen o por determinadas etapas históricas desde ópticas muy diferentes, sobresaliendo tanto estudios empíricos como culturales, de narrativas y victimológicos como el informe sobre el impacto del terrorismo en la sociedad vasca de López Romo (2015) y los análisis de este con Fernández Soldevilla (2012) sobre el nacionalismo vasco radical o los de este último en solitario (2015, 2016, 2018 y 2021) sobre los mecanismos para comprender desde distintos frentes la ideología, acciones, estrategia y objetivos de ETA. Asimismo, recientemente se ha publicado la obra de Fernández Soldevilla y Jiménez (2020) sobre el terrorismo en la Transición, que se centra en 1980: el año más mortífero de ETA durante la citada etapa.

Todos estos trabajos contribuyen a constatar que en los últimos años se han publicado cada vez más estudios desde la narrativa de las víctimas de las acciones terroristas, fruto de los avances y cambios en la construcción del relato sobre el terrorismo que las ha colocado en primer plano y que ha permitido que los victimarios hayan pasado a ocupar un lugar subsidiario. No en vano, el rol que ha desempeñado el Centro Memorial de las Víctimas del Terrorismo (CMVT), ubicado en Vitoria y dirigido por Florencio Domínguez, a la hora de fomentar este tipo de investigaciones ha sido notable por la publicación de numerosas monografías e informes. Este impulso ha convergido con los intereses académicos de diferentes departamentos universitarios, de los que sobresalen la Universidad del País Vasco, la Universidad de Deusto o la Universidad de Navarra, que se han volcado en la realización de estudios desde la óptica de las víctimas. Y, como se ha señalado, ha permitido que éstas se hayan situado en el centro del relato.

Algunas obras y trabajos de referencia al respecto son el pionero acercamiento a esta cuestión desde la perspectiva indicada realizado por Calleja (1997 y 2005); el artículo sobre la selección de las víctimas de ETA de De la Calle y Sánchez-Cuenca (2004); el análisis comparado de Azcona y Re (2009) sobre las víctimas de ETA y otros terrorismos revolucionarios; y ya más recientemente los estudios empíricos de Martín Peña (2013) sobre la victimización de los amenazados por ETA; de Leonisio (2013), Llera (2013) y Llera y Leonisio (2015) sobre las víctimas secuestradas, el impacto del terrorismo y la aparición de las víctimas en el discurso político; los avances de Abella-Uyarra (2016) sobre victimización terrorista; o los más específicos sobre mujeres víctimas de ETA de Rodríguez (2017) y García Varela (2019). 
De este modo, a la par que se han ido editando estudios como los anteriormente señalados, varios de ellos centrados en las diferentes narrativas sobre el terrorismo, cada vez han visto la luz más trabajos sobre la memoria de este fenómeno y los usos del pasado en el País Vasco posterrorista. Sobresalen, así, los estudios de Alonso, Domínguez y García-Rey (2010) centrado exclusivamente en realizar un análisis de los atentados y de las víctimas del terrorismo; el macroestudio de Marrodán, Araluce, García de Leániz y Jiménez (2013) sobre el impacto del terrorismo en Navarra; los trabajos de Arregi (2015), Arrieta (2015) y Rodríguez Jiménez (2017) sobre las narrativas de la historia de ETA; los informes y ensayos corales de Sáez de la Fuente (2017), y de esta con Bilbao (2020), y Ugarte (2018) sobre la extorsión de ETA al mundo empresarial; la tesis y los trabajos de Jiménez (2018a, 2018b y 2019) sobre la importancia del testimonio de las víctimas; la monografía de De Pablo, Mota Zurdo y López de Maturana (2018) sobre la transmisión del relato del terrorismo a través de la televisión y de De Pablo (2017) y Labiano (2019) sobre esta misma cuestión a través del cine; el libro sobre la primera víctima de ETA (José Antonio Pardines) de Domínguez y Fernández Soldevilla (2018); el informe sobre los heridos y olvidados de ETA de Marrodán y Jiménez (2019); las obras coordinadas por Rivera (2018 y 2019), y de este con Mateo (2020), sobre los usos del pasado y las narrativas del terrorismo; la tesis de Moreno (2019) sobre Gesto por la Paz; y el reciente trabajo coordinado por Pérez (2021) sobre la historia y la memoria del terrorismo en Euskadi. Todas estas aportaciones, que son tan solo una breve selección de las más recientes o significativas, vienen a completar el camino abierto por otras obras, ya canónicas y también selectas, como las de Jáuregui (1985), Sullivan (1988), Garmendia (1996), Domínguez (1998a, 1998b, 2003, 2011), Reinares (2001), Sánchez-Cuenca (2001), Muro (2008), Casquete (2009) y Carnicero y Rivera (2010), siendo esta última de especial significado al haber participado en ella expertos de primer orden como Fernando del Rey o Martín Alonso.

Estos y otros estudios sobre el terrorismo como los de González Calleja (2012), junto con los de Álvarez Bragado (2018) y Mees (2020) sobre el problema vasco, son primordiales para conocer cuáles fueron las causas y las consecuencias de la violencia política en el País Vasco, en Navarra y en toda España. También son fundamentales para profundizar en su estructura organizativa, sus motivaciones ideológicas, el perfil de sus militantes y su trayectoria en el contexto local, regional, nacional e internacional, así como sus implicaciones políticas y sociales.

Igualmente, junto a todos los trabajos citados, se suman otros sobre el tema basados en las nuevas metodologías de análisis que se están utilizando en su estudio como son el enfoque intersubjetivo y el de las emociones, que están siendo determinantes para poner en un primer plano de análisis a las víctimas, dignificándolas y poniendo en valor su historia de vida, abriendo nuevos campos de investigación, como se ve en Hidalgo (2018) o Hidalgo y Comonte (2020). Junto a ellas se han publicado otras obras que tratan de conocer también la perspectiva del victimario, personificándole y ofreciendo un perfil psico-político, como se ve en Buckley (2020) o en Gago y Ríos (2021).

Pero, aunque se ha avanzado mucho en el conocimiento de ETA y en el relato de sus acciones a través de la narrativa de las víctimas, pues los trabajos señalados son, como se ha indicado, el principal punto de referencia y piedra de toque para conocer su funcionamiento y recorrido histórico, lo cierto es que caben realizar otro tipo de análisis sino distintos, al menos complementarios. Cabe continuar incidiendo en la atención a las víctimas desde perspectivas como la del territorio, sobre todo porque, pese a los avances historiográficos reseñados, lo indicado por De la Calle y Sánchez Cuenca (2004) sobre el análisis de las víctimas continúa siendo válido: "apenas se ha desarrollado en la extensa literatura sobre terrorismo" (p. 54). Este enfoque permite obtener nuevos matices que ayuden a completar el perfil tanto de las víctimas como el de los perpetradores de estas acciones, entendiendo mejor la elección de los objetivos terroristas de acuerdo con su ubicación geográfica y contraponiendo las acciones cometidas en el ámbito urbano con las realizadas en zonas rurales.

\section{METODOLOGÍA Y FUENTES}

Esta investigación sobre las víctimas de las FCSE se basa en la bibliografía disponible, en la prensa y en fuentes archivísticas de algunos de los municipios en los que se produjeron los atentados. Para su elaboración, 
se han tomado de partida una serie de trabajos que se consideran fundamentales en el enfoque elegido para este estudio: el análisis de De la Calle y Sánchez-Cuenca (2004) sobre la selección de las víctimas de ETA; el trabajo de Sánchez-Cuenca (2009) sobre las variaciones en la letalidad de las acciones de ETA; el informe de López Romo (2015), el estudio más completo hasta el momento sobre los contextos históricos del terrorismo en el País Vasco y la consideración social de sus víctimas; y los trabajos de Llera y Leonisio (2015), Company Alcañiz (2016), Jiménez (2019) y Jiménez y Marrodán (2019) sobre las víctimas de ETA tanto en los "años de plomo" como en su estigmatización y su condición de secuestradas y heridas.

A través de estos modelos, y partiendo de la información obtenida de los archivos municipales de las diferentes localidades guipuzcoanas, vizcaínas y alavesas en las que se produjeron los atentados, se realiza un análisis histórico, territorial y estadístico de las víctimas de las FCSE en el periodo de consolidación democrática. Este trabajo también bebe de la información proporcionada por "El mapa del terror": un memorial online sobre las víctimas del terrorismo asesinadas en España realizado por el Colectivo de Víctimas del Terrorismo en el País Vasco (COVITE), en colaboración con el CMVT, la Fundación Víctimas del Terrorismo y la Dirección General de las Víctimas del Terrorismo, del que se ha obtenido el lugar de procedencia y del asesinato de la víctima, entre otra información.

Este artículo es, por tanto, un acercamiento a la cuestión desde las variables señaladas en la introducción: procedencia, lugar del atentado y cuerpo policial/militar. Es, asimismo, un análisis de carácter positivista, cuantitativo y de relato descriptivo, pero no exento de interpretación, pues el objeto de estudio se enmarca en su correspondiente contexto y se acude a metodologías y enfoques propios de la historia social y de la nueva historia política para tratar de establecer una visión de conjunto lo más completa posible sobre la violencia terrorista contra las FCSE entre 1982 y 1994.

\section{CONTEXTO HISTÓRICO: DOCE AÑOS DE TERROR Y SUFRIMIENTO PARA LAS FCSE EN EUSKADI}

\subsection{El inicio del descenso de la virulencia de los años de plomo}

Durante la etapa de guerra de desgaste, ETA se dedicó a la selección de sus víctimas tratando de conseguir con esta estrategia tanto de maximizar los daños de sus objetivos como de conseguir la aceptación y apoyo a sus acciones. Se volcó en perseguir, entre otros, a las FCSE siguiendo la teoría, ya expuesta a finales de la década de 1960, de que debía desaparecer de Euskadi la infraestructura y el aparato del Estado. No en vano, su trayectoria avalaba esta decisión: una de las primeras bombas que colocó fue en una comisaría de Bilbao (1959); y sus dos primeros asesinatos fueron un agente de la Guardia Civil y otro de la Policía (1968) en los municipios guipuzcoanos de Aduna e Irún, respectivamente. De hecho, para la organización terrorista vasca, el primer cuerpo policial era "la fuerza principal de represión imperialista en Euskadi sur (los territorios vascos situados administrativamente en España)", mientras que el segundo lo era «en las ciudades o centros industriales». Durante la democracia, que es el periodo que aquí ocupa, ETA continuó actuando de este modo incrementando la intensidad de sus acciones en Euskadi y Navarra (De la Calle \& Sánchez-Cuenca, 2004, p. 56; Fernández Soldevilla, 2020, pp. 111 y ss.; Sánchez-Cuenca, 2009; Domínguez, 2020, p. 133; Domínguez, 2006, p. 304).

Siguiendo la estrategia apuntada, en la década de 1980, ETA atentó contra las FCSE por ser los representantes del Estado en el País Vasco. Pero, en 1982, lo hizo reiteradamente con la finalidad de obtener un mayor impacto mediático de sus acciones, aprovechando la celebración del Mundial de fútbol en España durante el verano de aquel año. La organización terrorista buscó con sus atentados que los medios de comunicación nacionales e internacionales ofrecieran la imagen de un país en conflicto, por lo que atacó a las FCSE con contundencia. El saldo de muertes fue importante, aunque relativamente más bajo si se compara con las 132 víctimas mortales (53 de ellas miembros de las FCSE) que sólo en 1980 fallecieron por actos de terrorismo (López Romo, 2015, pp. 127-131; Fernández \& Jiménez, 2020).

En 1982 la dinámica de asesinatos de miembros de las FCSE en Euskadi entró en descenso, como se observa en el gráfico 1, pero ETA y los CAA segaron la vida a 22 personas (10 guardias civiles, 6 policías 
y 3 militares). Ese año ETA anunció que convertiría al Instituto Armado y sus edificios (las casas cuartel) en objetivo prioritario. Sin embargo, pese a esta declaración de intenciones, los datos en Euskadi para el periodo 1982-1994 revelan que no hubo una diferencia tan marcada entre los diferentes cuerpos de seguridad, ya que si se compara con la Policía se comprueba que esta también sufrió un alto número de bajas, como refleja el gráfico 2 .

En cualquier caso, en 1982 el número de atentados mortales contra las FCSE en Euskadi entró en ciclo de descenso, como se constató en 1983 al disminuir ligeramente el número de víctimas de este tipo. Si bien, el saldo de atentados mortales fue de uno cada tres semanas, lo que contribuyó a que se sembrara el pánico en los cuerpos policiales y las Fuerzas Armadas. De este modo, la organización terrorista consiguió su propósito: crear zozobra e inestabilidad, sobre todo para el Gobierno de la UCD, que hubo de hacer frente a momentos de gran tensión, como el golpe de Estado de febrero de 1981. Y es que ETA planteó una estrategia ofensiva: boicotear cualquier tipo de medida conducente al cese de la violencia, como sucedió con sus exigencias al presidente del Gobierno Vasco, Carlos Garaikoetxea (1980-1985), cuando este emplazó a ETA a conversaciones; es decir, la organización terrorista solicitó como conditio sine qua non para dejar las armas que el Gobierno de España aceptara la alternativa KAS (un programa político independentista que solicitaba, entre otras cosas, la expulsión de las FCSE del País Vasco) y que las entrevistas fueran públicas (Muñoz Bolaños, 2021; Domínguez, 2006, p. 298).

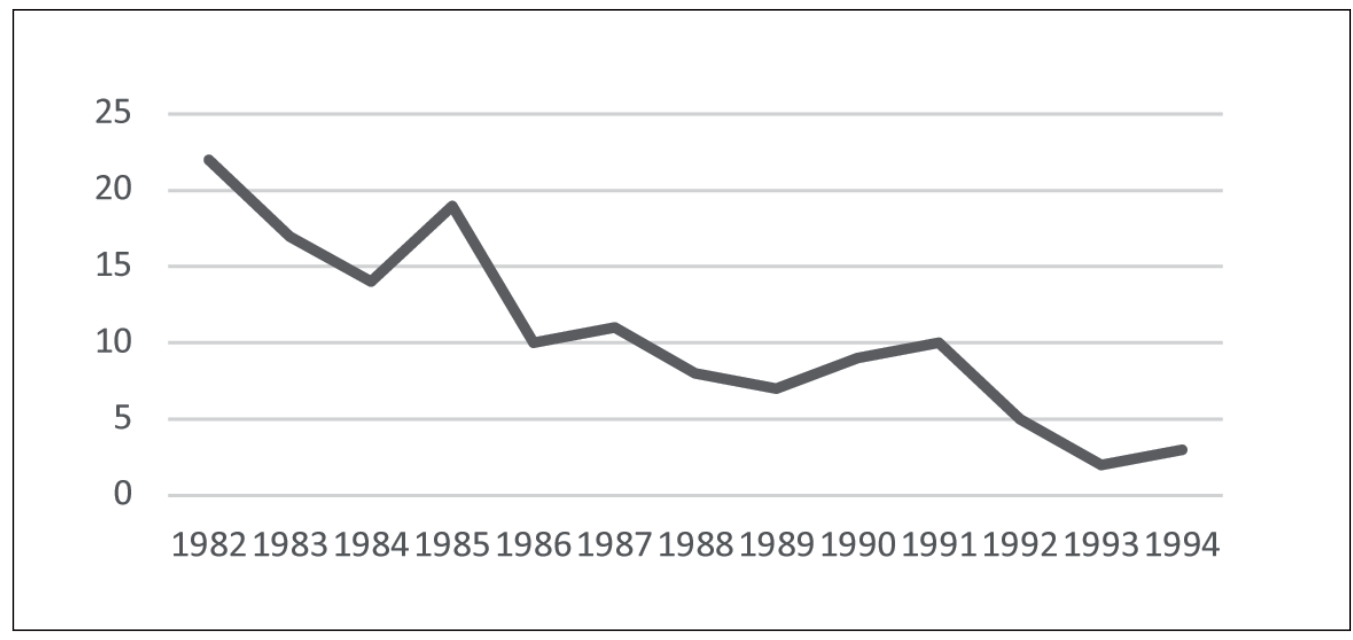

Gráfico 1. No de víctimas mortales de las FCSE en Euskadi. Fuente: Elaboración propia sobre los datos obtenidos de López Romo (2015).

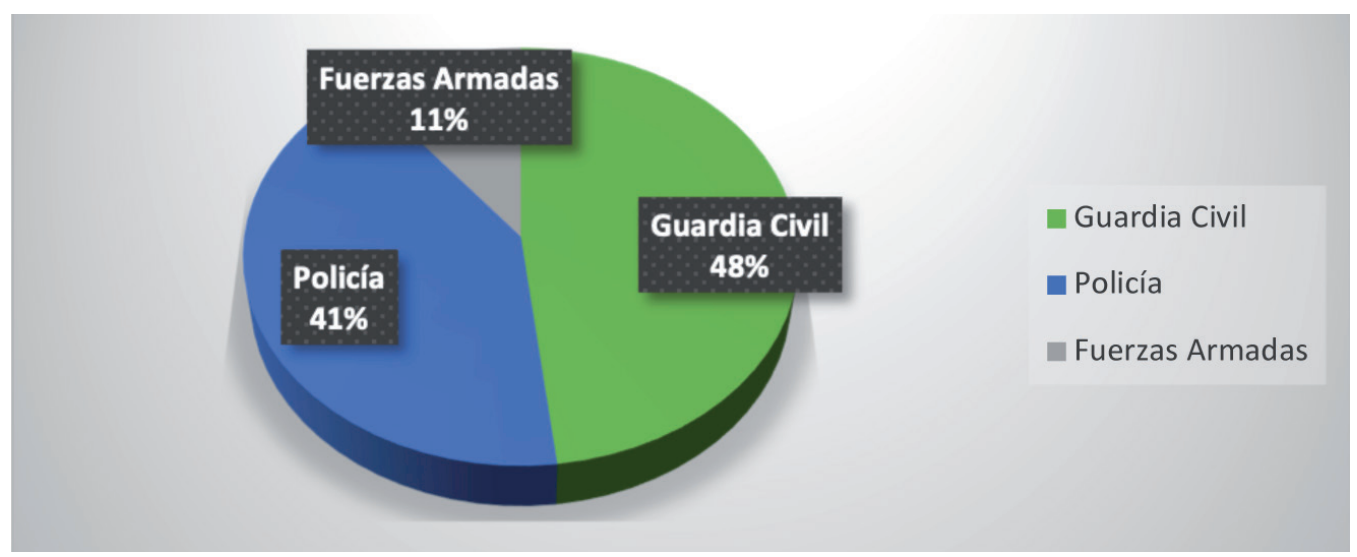

Gráfico 2. Porcentaje de víctimas de las FCSE fallecidas por acciones de ETA y CAA. Fuente: Elaboración propia sobre los datos obtenidos de López Romo (2015). 


\subsection{La legislatura socialista: estrategias y cambios para luchar contra el terrorismo.}

En octubre de 1982, el PSOE accedió al Gobierno tras obtener una abrumadora victoria en las elecciones generales, sacando una importante distancia tanto al segundo partido más votado, la coalición entre Alianza Popular (AP) y el Partido Demócrata Popular (PDP), como al tercero, Unión del Centro Democrático (UCD), que pasó a ocupar un lugar casi testimonial si se compara con años precedentes. En otras palabras, que el partido de Felipe González hubiera logrado casi un 50 por ciento del total de escaños era algo inimaginable un año y medio antes, cuando Adolfo Suárez estaba al frente del Gobierno de España y de la UCD. En Euskadi, el Partido Nacionalista Vasco (PNV) constató su posición hegemónica, y muy cerca de ellos se situaron los socialistas vascos, que superaron a HB. El acceso de los socialistas al poder cerró un proceso, el de la Transición, y abrió un periodo nuevo, el de la consolidación democrática.

Los vientos de cambio fueron evidentes en las ambiciosas propuestas del Gobierno González, cuya hoja de ruta fue facilitar el asentamiento de la democracia; reconducir la economía, acabar con el paro y la inflación; poner fin al terrorismo a corto plazo; e integrar a España en la Comunidad Económica Europea (CEE). A través de estas líneas maestras, el PSOE consiguió reformar el país de forma progresista, estructuró el Estado del bienestar, afianzó la democracia y disipó las amenazas golpistas. Pero se vio afectado por la fragmentación social derivada de la corrupción, por la utilización de métodos extrajudiciales para combatir el terrorismo y por la continuidad de España en la OTAN, así como por la intensificación de los ataques de ETA, GRAPO y CAA, entre otros grupos (Fusi, 2012, p. 245).

Así las cosas, 1983 no fue un año muy diferente en lo que se refiere a las víctimas de las FCSE en Euskadi. Aunque su número fue ligeramente inferior al del año anterior, lo cierto es que ETA y los CAA mantuvieron una dinámica muy alta de atentados. Durante este año, se constató el fracaso de las iniciativas de Garaikoetxea para entrevistarse con HB y crear una mesa por la paz: la coalición nacionalista vasca radical exigió que el Gobierno se sentara a negociar con la banda terrorista. Los asesinatos de miembros de las FCSE producidos en los primeros meses del año, pero sobre todo el del capitán de Farmacia Alberto Martín Barrios en el otoño, hicieron que el Gobierno de España decidiera no sentarse siquiera a hablar con PNV y HB. A partir de entonces los socialistas etiquetaron a HB de "brazo político de ETA-M" e interpretaron que tanto su estrategia como la de ETA iban indisolublemente unidas (Alonso, Domínguez \& García Rey, 2010, p. 425; Sánchez \& Simón, 2017, p. 229).

Ese mismo año, el Ministerio del Interior desplegó como parte de su estrategia antiterrorista el Plan Zona Especial Norte (ZEN) y tres de sus cargos crearon clandestinamente los Grupos Antiterroristas de Liberación (GAL), un grupo parapolicial en cuya creación estuvieron implicados directamente miembros del Gobierno González que de 1983 a 1987 acabó con la vida de 27 personas, en su mayoría miembros de ETA y afines, aunque hubo víctimas sin ningún tipo de vínculo con la organización nacionalista vasca radical.

Durante la legislatura socialista, el Gobierno de España se propuso atajar de raíz un problema cardinal para frenar las acciones terroristas: el santuario francés. El sur de Francia se había convertido desde la década de 1960 en un refugio para los miembros de ETA, desde donde planificaban sus acciones y a donde escapaban tras cometerlas. Por eso, el presidente Felipe González presionó al Elíseo para que adoptara otra actitud hacia ETA y, de este modo, tratar de achicar el flujo de atentados y muertes de miembros de las FCSE. El Ejecutivo socialista interpretó del siguiente modo los datos: desde su acceso al poder la mayor parte de los atentados se habían cometido en Gipuzkoa, un territorio próximo a la frontera y que, por consiguiente, aseguraba tanto la huida de los terroristas como el diseño de sus acciones sin el acoso policial. Los acercamientos entre los gobiernos de España y Francia que se realizaron en noviembre de ese año fueron, precisamente, para acabar con esta situación, pero hasta que se llegó a un acuerdo de cooperación, la espiral de violencia no dio tregua a las FCSE (Morán, 1996).

Tras el acceso de José Barrionuevo al Ministerio del Interior y de Narcís Serra al Ministerio de Defensa, la Guardia Civil comenzó a ocupar un papel destacable en la lucha antiterrorista. De hecho, así se entiende que la cifra de agentes asesinados de este cuerpo policial en Euskadi ascendiera progresivamente a partir de diciembre de 1982, con nueve muertes durante el primer año del Gobierno del PSOE, como se puede comprobar en el gráfico 3. 
Gráfico 3. Total de víctimas mortales de las FCSE en Euskadi desde el acceso de Barrionuevo y Serra. Fuente: Elaboración propia sobre los datos obtenidos de López Romo (2015).

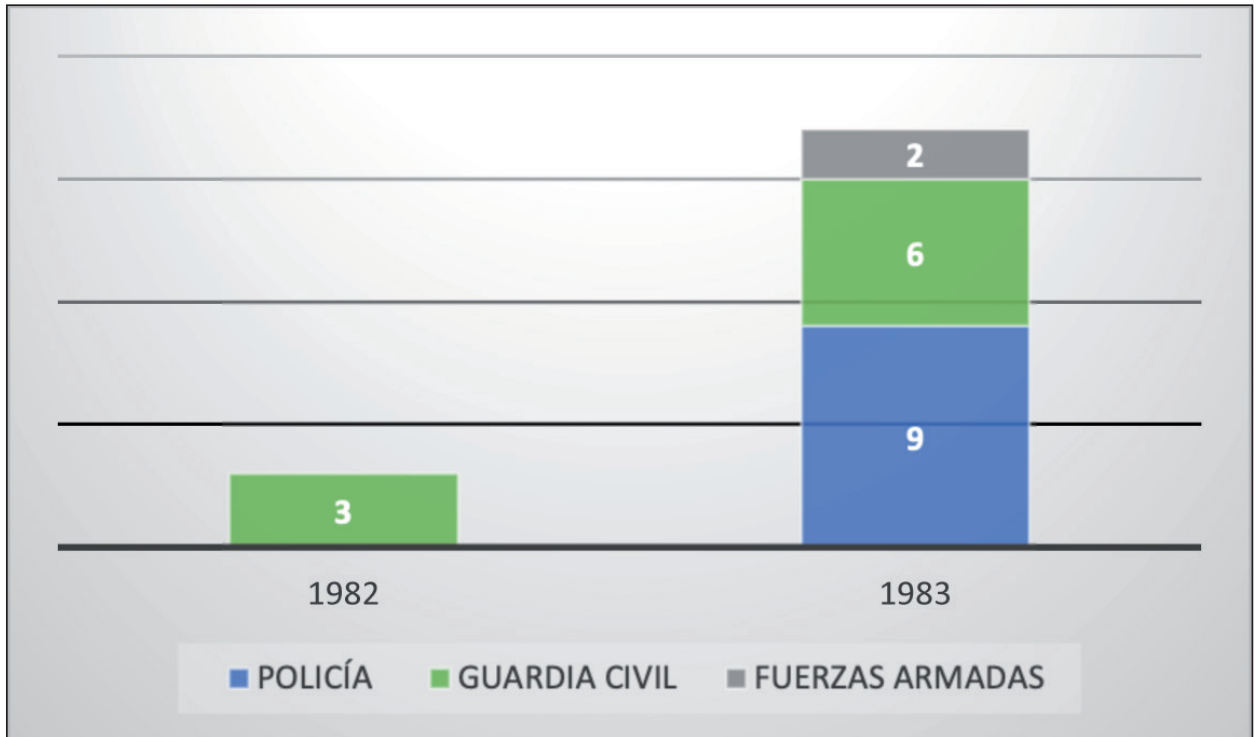

Durante 1983, una parte de la sociedad vasca comenzó a dar muestras de su posicionamiento contra el terrorismo y a favor de las FCSE. No era la primera vez, pues anteriormente hubo manifestaciones contra la violencia, como ha documentado López Romo (2015) con la convocatoria que hizo el PCE de Portugalete (Bizkaia) en 1978 tras el asesinato del periodista José María Portell o las que se produjeron en 1981 en Bilbao con motivo del asesinato del ingeniero-jefe de la central nuclear de Lemoiz (Bizkaia) José María Ryan (López Romo, 2012). Sin embargo, conviene poner en valor que en el otoño de ese año los gestos de repulsa hacia ETA y el terrorismo, producidos con motivo del asesinato de Martín Barrios (natural del País Vasco), porque fueron un auténtico punto de inflexión: se trató de una de las primeras manifestaciones multitudinarias de condena en la que la víctima fue un miembro de las FCSE. En el ayuntamiento de Bilbao, donde éste estaba avecindado, se generó una importante controversia: en primer lugar, porque la condena se produjo diez días después del atentado y, segundo, porque el edil de HB, Taxio Erkizia, tildó las manifestaciones de repulsa de "implícita defensa del terrorismo de Estado" (AMA Bilbao, 28-10-1983).

La falta de empatía de HB hacia las víctimas de las FCSE fue habitual durante estos años, al igual que su postura hacia las instituciones: tras las elecciones al Parlamento Vasco de febrero de 1984, en las que fue la tercera fuerza política más votada, continuó negándose acudir a la Cámara Vasca. Durante ese año, el GAL, que ya había cometido varias acciones desde 1983, siguió muy de cerca a los militantes de ETA en Francia con la finalidad de eliminarlos; y la Guardia Civil comenzó a realizar operaciones de desarticulación importantes: acabó con dos comandos de ETA y detuvo a varios colaboradores. Estos éxitos motivaron que la organización terrorista continuara con su fijación por las FCSE, aunque las cifras fueran ligeramente inferiores con respecto a años previos. Si bien, a pesar de que la Guardia Civil fue el cuerpo más azotado en Euskadi durante 1984, las Fuerzas Armadas sufrieron el mayor número de bajas de todo el periodo aquí estudiado, como se observa en el gráfico 4 (Granja, De Pablo \& Rubio, 2020, p. 268; Sánchez \& Simón,, 2017, p. 241).

Ante el mantenimiento continuado de la violencia, en el verano de 1984, el ministro del Interior anunció su disposición a entrevistarse con ETA en un encuentro a tres bandas al que también acudieran HB y el Gobierno francés. La organización terrorista interpretó este gesto como un síntoma de debilidad y, por eso, para negociar desde una posición de fortaleza aumentó sus acciones. Esa estrategia contribuyó a su desgaste y, en consecuencia, a la debilitación de la organización, sumida desde 1978 en un insostenible ciclo alto de violencia, que expuso demasiado a sus comandos. A esta circunstancia se sumaron los éxitos policiales indicados, que trajeron consigo un descenso del número de las células terroristas. ETA perdió, por este motivo, varios comandos legales (creados exprofeso para atentar), responsables del 80 por ciento de los actos terroristas cometidos, según ha estudiado Domínguez (2006, pp. 324-325). 


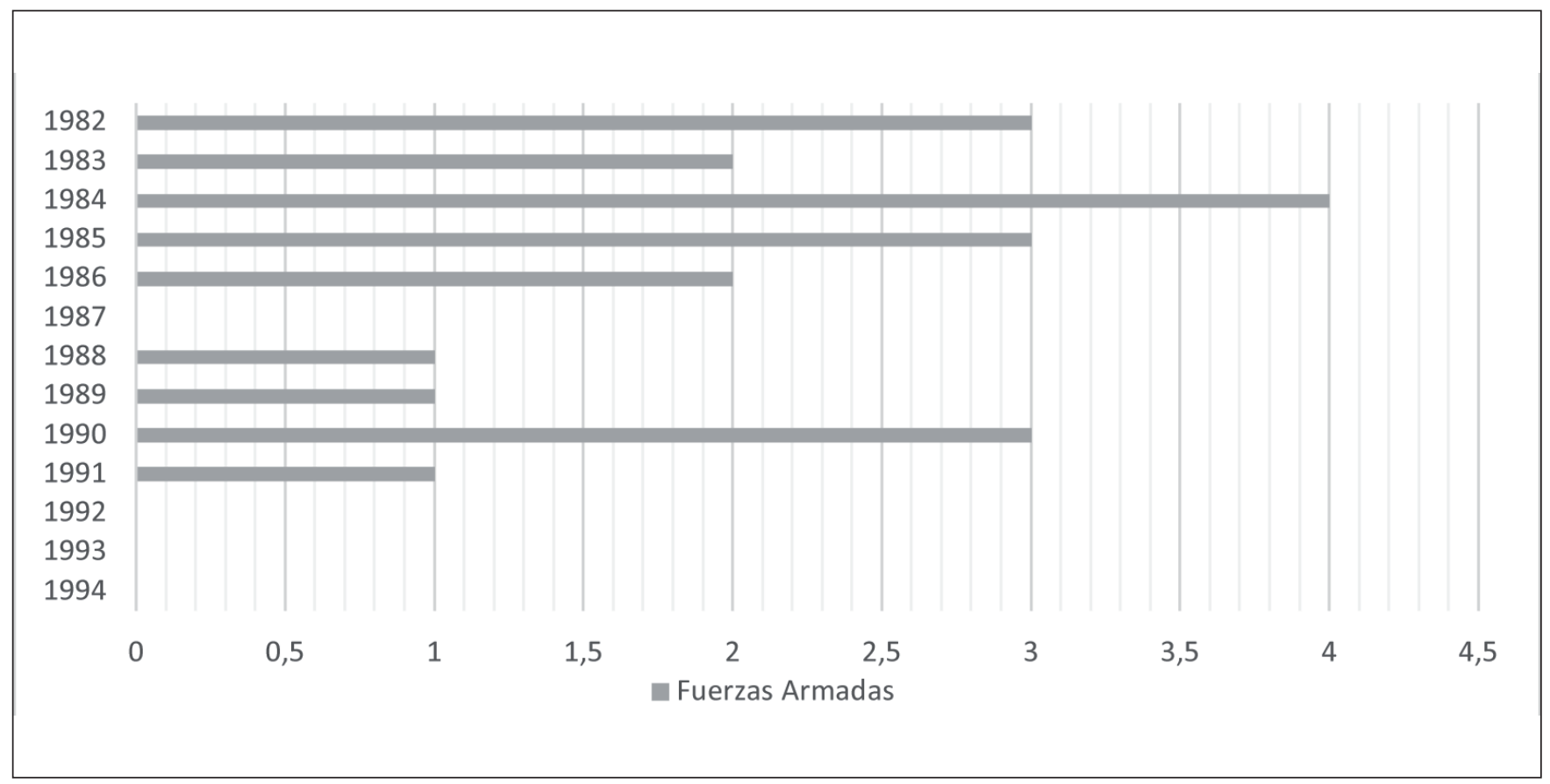

Gráfico 4. № de víctimas mortales de las Fuerzas Armadas en Euskadi. Fuente: Elaboración propia sobre los datos obtenidos de López Romo (2015).

Por este motivo, pronto, las FCSE fueron testigos de un nuevo modus operandi: el coche-bomba. Aunque la mayor parte de los atentados continuaron siendo el tiro en la nuca y el disparo a bocajarro, la caída de los comandos citados y el aumento de la capacidad operativa de ETA, que planificó más atentados de acuerdo con su estrategia de negociación, hicieron que la organización comenzara a decantarse por la opción de la bomba-lapa. En este sentido, aunque en 1985 hubiera un descenso del número de atentados a nivel nacional, en Euskadi hubo un repunte del número de víctimas de las FCSE, que coincidió con la negociación de un acuerdo de colaboración entre los Gobiernos de España y de Francia para frenar a ETA (Domínguez, 1998, p. 219; Morán, 1996, p. 220).

\subsection{Discontinuidades y altibajos}

El repunte de 1985 coincidió también con un hecho cardinal: la mayoría de los atentados se produjeron en Gipuzkoa, principal territorio de actuación de José Antonio López Ruíz Kubati, uno de los etarras más sanguinarios, que estuvo implicado en el asesinato de varios miembros de las FCSE en los que utilizó tanto el tiro en la nuca como el coche bomba. El volumen de atentados en este territorio (gráfico 5) está ligado a varios factores, algunos ya apuntados: el apoyo social que ETA tenía en la provincia, su situación fronteriza con Francia y las posibilidades que esta circunstancia les brindaba para huir y obtener refugio.

Asimismo, en las imágenes 1 y 2 puede observarse cómo la mayor parte de los atentados cometidos por ETA en Gipuzkoa entre 1984 y 1986 se concentraron en lugares próximos a la frontera con Francia, concretamente en las comarcas de Donostialdea y Bajo Bidasoa, y, en zonas cercanas a diferentes cordilleras y parques naturales, aprovechando el relieve montañoso de la comarca del Alto-Bajo Deba.

En 1986 el cerco a ETA comenzó a estrecharse: el gobierno galo, cuya concepción sobre la organización vasca había sido la de héroes antifranquistas, cambió de actitud y comenzó a obstaculizar su actividad en Francia. Primero, por la actividad del GAL, y, segundo, por las acciones de los nacionalistas vascos radicales contra intereses franceses. ETA era el principal condicionante de la política vasca y de la cotidianidad española, y los franceses temieron que sus departamentos situados al sur pudieran ser escenario de un repunte de la violencia en su país (Morán, 1996). 
Gráfico 5. No de víctimas mortales de las FCSE por provincias. Fuente: Elaboración propia sobre los datos obtenidos de López Romo (2015).
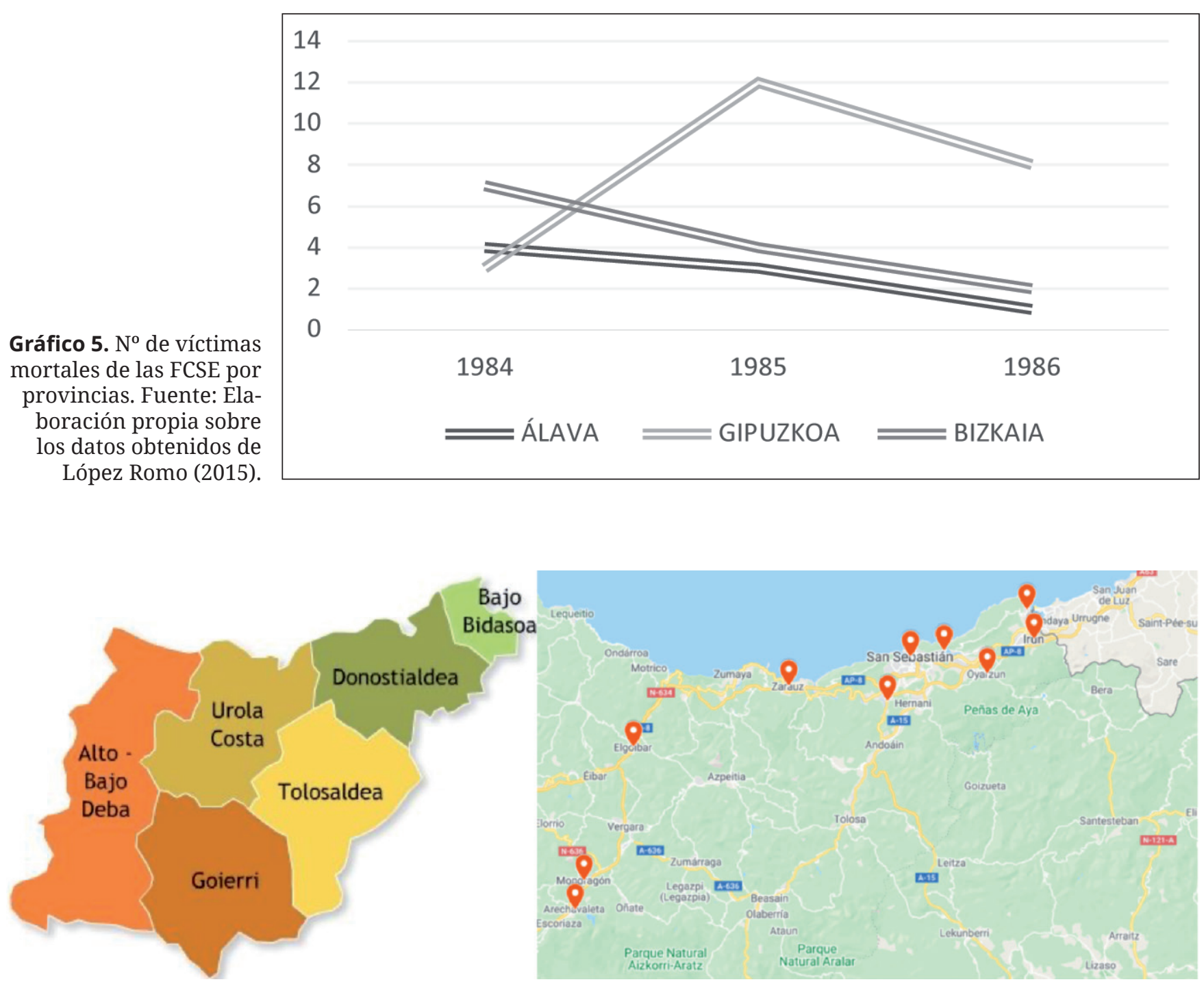

Imagen 1. (Izq.) Comarcas de Gipuzkoa. Fuente: Pinterest. Imagen 2. (Dcha.) Atentados de ETA en Gipuzkoa (19841986). Fuente: Elaboración propia en MyMaps.

En este sentido, el atentado con coche-bomba contra el gobernador militar de Gipuzkoa, Rafael Garrido Gil, que se produjo en octubre de 1986 en el marco de la celebración de las elecciones autonómicas, fue interpretado inicialmente como una regresión a situaciones anteriores. Pero lo cierto es que la curva de fallecidos en atentado de las FCSE se estabilizó y en Euskadi entró en descenso: en 1987 se constató una disminución del número de víctimas de este tipo (gráfico 6). Fuera de este territorio, en cambio, ETA cometió dos de sus acciones más crueles: la bomba de Hipercor en Barcelona y la de la Casa Cuartel de la Guardia Civil en Zaragoza (Avilés, 2010).

Durante 1987 el Gobierno de España continuó explorando la opción de negociar con ETA para lograr el fin de la violencia y así, después de varios contactos, inició las conocidas como conversaciones de Argel. Este acercamiento coincidió con una mejora de los métodos de investigación, las vías de seguimiento y la infiltración en ETA por parte de la Guardia Civil, que comenzó a obtener resultados positivos, fruto de un cambio de estrategia consistente en la realización de arrestos selectivos de personas ligadas estrechamente con la organización. Supuso un número menor de arrestos, pero contribuyó al descenso de la actividad de ETA, principalmente en Gipuzkoa. Entre 1987 y 1988, también hubo cambios en el ámbito vasco: la mayor parte de los partidos políticos se unieron para sumar esfuerzos contra la violencia firmando varios pactos y acuerdos contra el terrorismo y para la pacificación y normalización de Euskadi, como fueron los de Madrid, Ajuria Enea y Pamplona (Sánchez Corbí \& Simón, 2017; Granja, De pablo \& Rubio, 2020, pp. 271-285). 


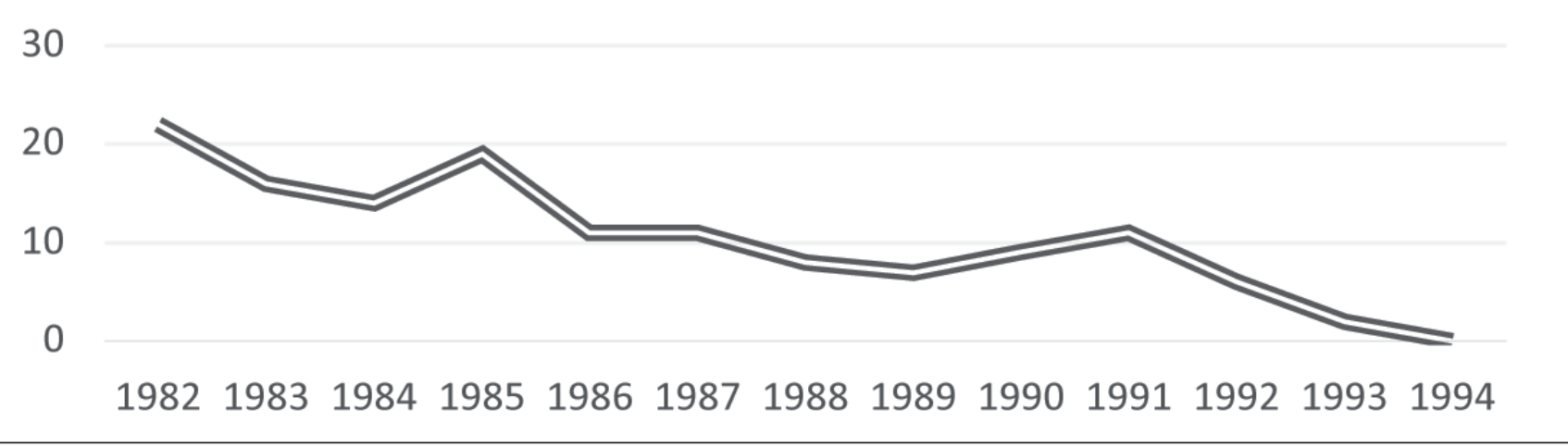

Gráfico 6. Total de víctimas mortales de las FCSE en Euskadi. Fuente: Elaboración propia sobre los datos obtenidos de López Romo (2015).

Fruto de los encuentros en Argel, en enero de 1989, ETA estableció una tregua para entablar negociaciones: el resultado fue un periodo de inactividad de tres meses, hasta que la organización terrorista dio un ultimátum al Ejecutivo socialista para acelerarlas, solicitando requisitos no pactados como condición para continuar con las conversaciones. El Gobierno González se negó y ETA retomó las armas el 6 de abril tras anunciar que quedaban "abiertos todos los frentes de lucha" (Vasco-Press, n 350, 3-IV-1989. El País, 13-IV-1989). Menos de una semana después, en Getxo (Bizkaia), segó la vida del sargento de la Guardia Civil José Calvo (El Correo, 13IV-1989). Durante este año, hubo lapsos de tiempo bastante amplios entre los atentados mortales contra las FCSE, como sucedió con los de los policías Juan Pedro González, de mayo, y José Ángel Álvarez, de octubre. Sin embargo, ello no fue óbice para que al año siguiente aumentara el número de víctimas de las FCSE en Euskadi.

En 1991, mientras el número de víctimas de la Policía Nacional y de las Fuerzas Armadas descendió en el País Vasco, las de la Guardia Civil experimentaron un importante aumento debido al papel jugado por este cuerpo policial en la lucha antiterrorista y a los esfuerzos de ETA por lograr el impacto mediático en un contexto marcado por la organización al año siguiente tanto de la Exposición Universal de Sevilla como de la celebración de los Juegos Olímpicos de Barcelona. La reactivación de los atentados y la fijación de ETA por hacer mella en el Instituto Armado en la ciudad hispalense y en la capital condal conllevó un descenso de las víctimas de las FCSE en el País Vasco. Esta bajada se notó, sobre todo, a partir de la detención tanto de la cúpula de ETA en Bidart (Francia) en 1992 como del éxito de otros operativos policiales, que obligaron a su dirección a optar por otras estrategias (Domínguez, 1998, p. 219).

En 1991, se constató definitivamente que las acciones de ETA contra las FCSE no solo tenían por objetivo a sus miembros, sino también a sus familias. La bomba-lapa que colocó en el coche del policía nacional Jesús Villamudria en Vitoria (Álava), que tuvo como principal consecuencia el fallecimiento de su hija Coro, de 17 años, y la adherida al automóvil del guardia civil Antonio Moreno en Erandio (Bizkaia), a finales de ese mismo año, que segó la vida de su hijo Fabio, de dos años, demostró bien a las claras que, en su lucha por lograr sus objetivos, ETA se llevaría por delante incluso a menores de edad. Ciertamente, ya lo había demostrado en el atentado contra la casa-cuartel de Zaragoza (y lo repetiría en la de Vic en 1991), pero estos atentados de ETA en Euskadi fueron especialmente escalofriantes por su justificación: "porque el enemigo utilice cobardemente a sus hijos para protegerse. [...] no hay que escatimar medios y arriesgar innecesariamente la vida de nuestros luchadores, que vale cien veces más que la del hijo de un txakurra [término despectivo para referirse a los miembros de las FCSE]" (Deia, 6-XI-2016).

En 1992 las víctimas mortales de las FCSE en el País Vasco continuaron descendiendo a la par que se recrudeció la actividad terrorista. La caída de su cúpula en Bidart obligó a explorar otras estrategias, como la de la "socialización del sufrimiento", consistente en un terrorismo callejero de menor intensidad (kale borroka), azuzado por HB y otras organizaciones afines. Este cambio de estrategia se mostró en el descenso de operatividad contra las FCSE, pues en 1993 sólo la Guardia Civil sufrió el azote mortal del terrorismo en el País Vasco. Al año siguiente, la Benemérita continuó siendo el principal objetivo, pese a que hubiera víctimas de la Policía. 


\section{RESULTADOS: ORIGEN Y FINAL DE LOS MIEMBROS DE LAS FCSE}

Durante el periodo de consolidación democrática, ETA y los CAA asesinaron a 63 agentes de la Guardia Civil, 54 de la Policía y 20 miembros de las Fuerzas Armadas en el País Vasco. Las cifras son muy elevadas para un periodo de poco más de una década, pero menores si se comparan con etapas precedentes, como ya se ha señalado. De igual modo, reforzando la afirmación de epígrafes anteriores de que Gipuzkoa fue el territorio más mortífero para las FCSE durante este periodo, en el gráfico 7 se comprueba que la mitad del total de fallecidos se produjo en la citada provincia. Fue seguida muy de cerca por Bizkaia y en lugar casi testimonial Álava; es decir, las dos provincias marítimas vascas concentraron el 90 por ciento de las víctimas mortales de las FCSE en el País Vasco durante este periodo.

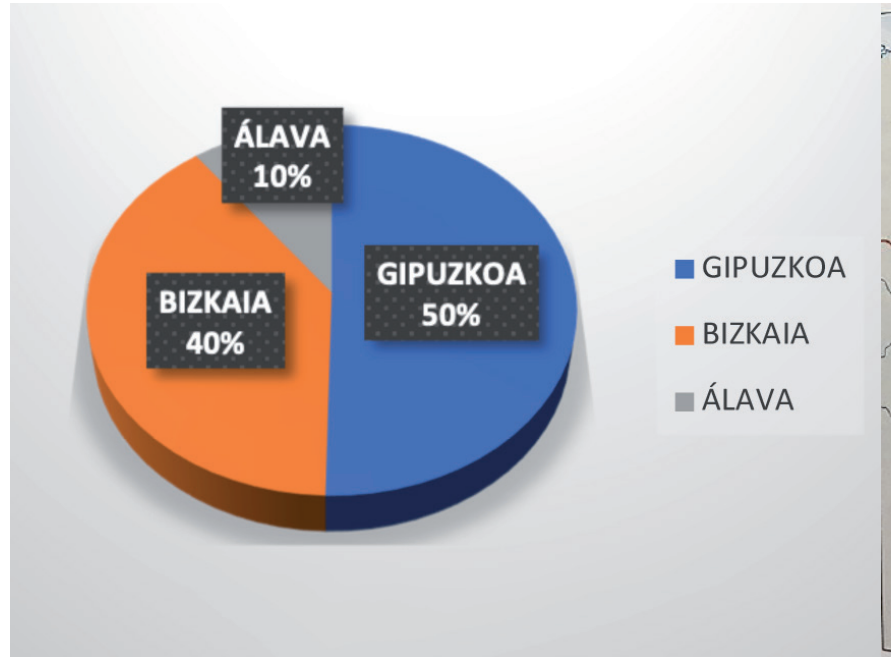

Gráfico 7. Víctimas de las FCSE fallecidas en atentado por ETA y CAA.

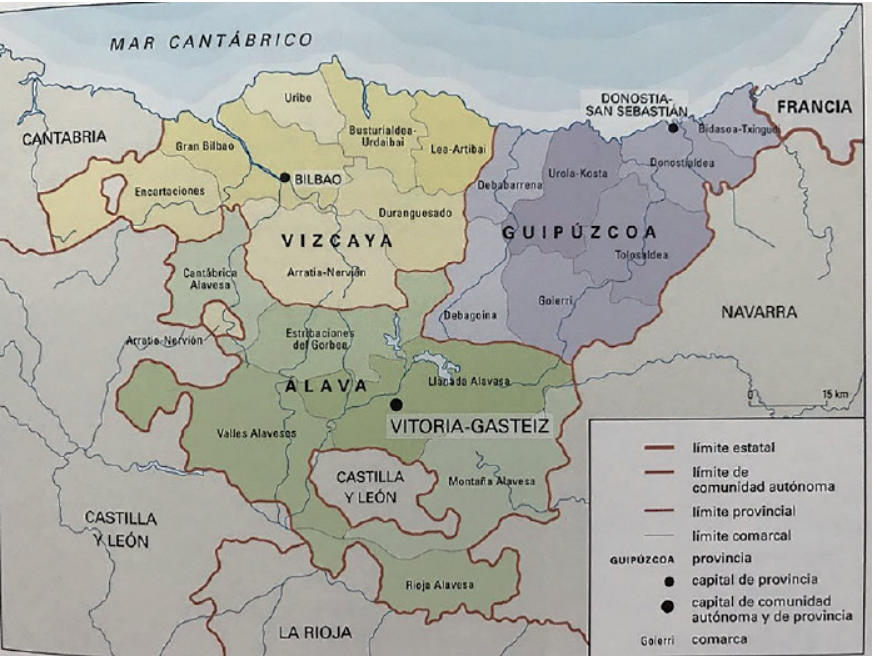

Imagen 3. Mapa político del País Vasco. Fuente: mapa.nom

En Gipuzkoa (gráfico 8) los municipios más mortíferos para las FCSE fueron en este orden los siguientes: San Sebastián, con 26 víctimas mortales; Errenteria e Irún con seis; Oiartzun y Pasaia con cinco; Oñati con tres; Ordizia, Getaria, Lasarte-Oria, Arrasate-Mondragón y Aretxabaleta con dos; y con una: Urnieta, Tolosa, Hondarribia, Elgóibar, Soraluze, Zarautz, Éibar y Andoain. Partiendo del número de atentados mortales cometidos en estos municipios, se obtiene también la siguiente información (gráfico 9): las comarcas guipuzcoanas en las que fallecieron un mayor número de agentes de las FCSE fueron Donostialdea, con 46; Alto-Bajo Deba con diez; Bajo Bidasoa con siete; Urola Kosta con tres; Goierri, con dos; y Tolosaldea, con una.

En Bizkaia, sucede algo similar a lo reflejado en Gipuzkoa (gráficos 10 y 11): la mayor parte de los atentados se concentraron en la capital, seguido de municipios situados en la comarca del Gran Bilbao, como Galdakao, Getxo, Santurtzi y Portugalete. Mientras que, por un lado, el Gran Bilbao concentró 44 de las 54 víctimas registradas para Bizkaia, en la comarca de Encartaciones y en la de Arratia-Nervión, esta última una de las cunas del nacionalismo vasco radical, no hubo víctimas de las FCSE. Si bien, en el resto de las comarcas sí hubo asesinatos: tres víctimas mortales tanto en Uribe Kosta, Busturialdea como Durangaldea. Por su parte, en Lea-Artibai, una zona también sociopolíticamente muy nacionalista, sólo hubo una.

En cuanto al territorio alavés, de nuevo, vuelve a ocurrir lo mismo que en las otras dos provincias (gráficos 12 y 13): la capital, Vitoria-Gasteiz, concentra el mayor número de víctimas mortales de las FCSE, con ocho agentes de policía. En esta ciudad, para el periodo estudiado, sólo fallecieron miembros del citado cuerpo policial, mientras que en otras partes del territorio como Elburgo, situado en la Llanada Alavesa, fallecieron tres guardias civiles. Por número de fallecidos, los municipios alaveses con víctimas mortales de las FCSE, aparte de los ya citados, fueron Salvatierra, Ayala y Legutio, los tres con una víctima cada uno. Con las comarcas alavesas sucede lo mismo que en las otras provincias: aquella que alberga a la capital concentra el 
mayor número de bajas. Tal es el caso de Vitoria-Gasteiz, con ocho; seguida de Llanada Alavesa con cuatro; y Ayala y Zuia-Estribaciones del Gorbea con una. En las comarcas de Añana, Montaña Alavesa y Rioja Alavesa no hubo fallecidos de esta tipología.

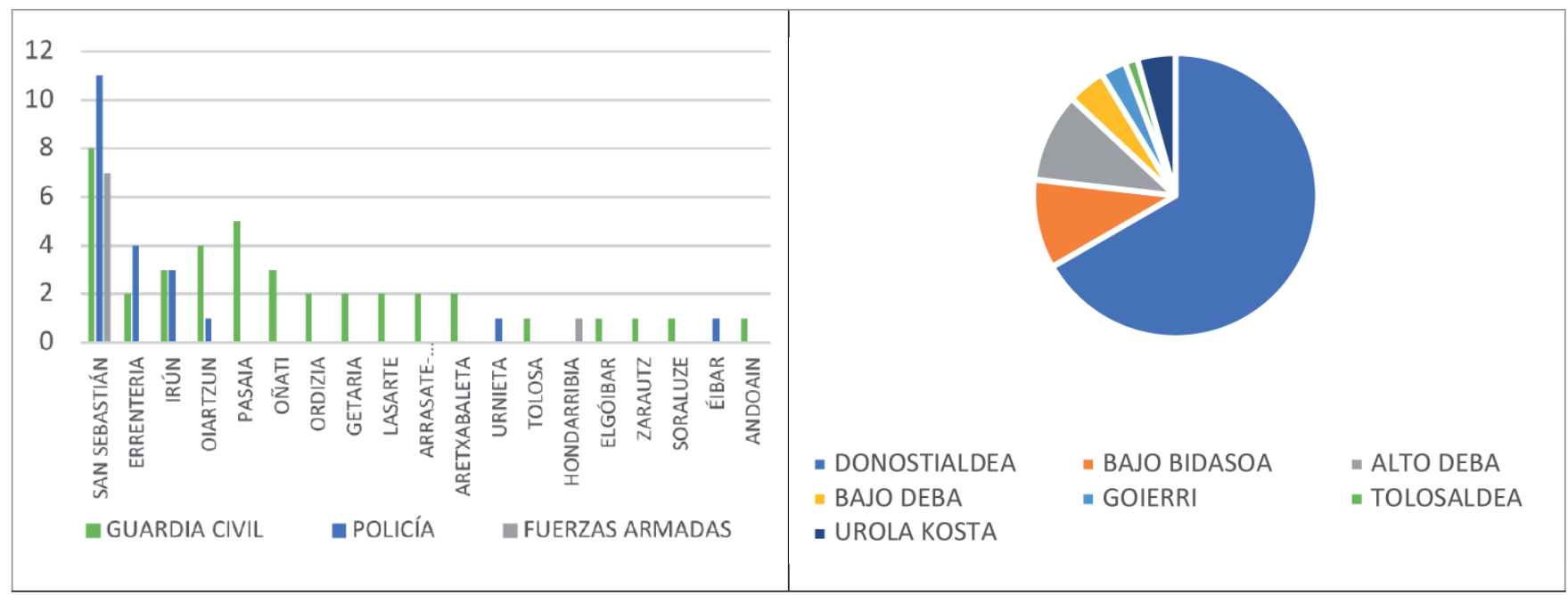

Gráfico 8. Víctimas morales de las FCSE por municipios de Gipuzkoa.

Gráfico 9. Porcentaje de víctimas de las FCSE por comarca en Gipuzkoa. Fuente: Elaboración propia sobre los datos obtenidos de López Romo (2015).

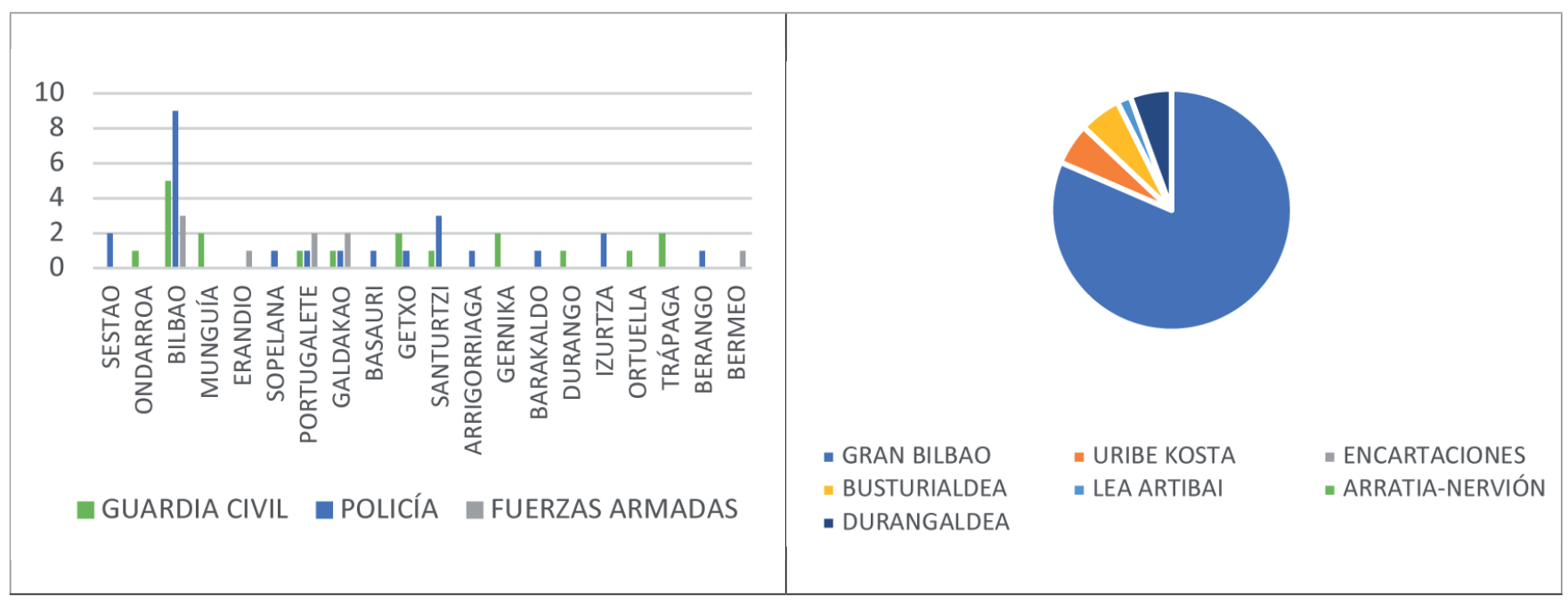

Gráfico 10. Víctimas mortales de las FCSE por municipio de Bizkaia.

Gráfico 11. Porcentaje de víctimas de las FCSE por comarca en Bizkaia. Fuente: Elaboración propia sobre los datos obtenidos de López Romo (2015).

Asimismo, si se discrimina el número de víctimas de las FCSE fallecidas en atentado terrorista sobre la base del cuerpo en el que sirvieron (Guardia Civil, Policía y Fuerzas Armadas) y, además, se examinan los datos por provincias (gráfico 14), se observa que es Gipuzkoa la que concentra el mayor número de víctimas de la Guardia Civil, con 40 fallecidos.

En Bizkaia, aunque su número también es alto, las cifras son inferiores, con 19 víctimas. No obstante, en este último territorio el número de policías fallecidos a manos de ETA y los CAA es el más alto de las tres provincias, con 25 víctimas. Lo mismo sucede en cuanto a los miembros de las Fuerzas Armadas caídos por acciones terroristas, con 11 víctimas mortales. Por el contrario, el caso de Álava es muy diferente, siendo sólo especialmente alto el número de policías caídos por violencia terrorista, pero si se compara con el resto de las provincias vascas es meramente testimonial para un periodo de doce años como el estudiado. 


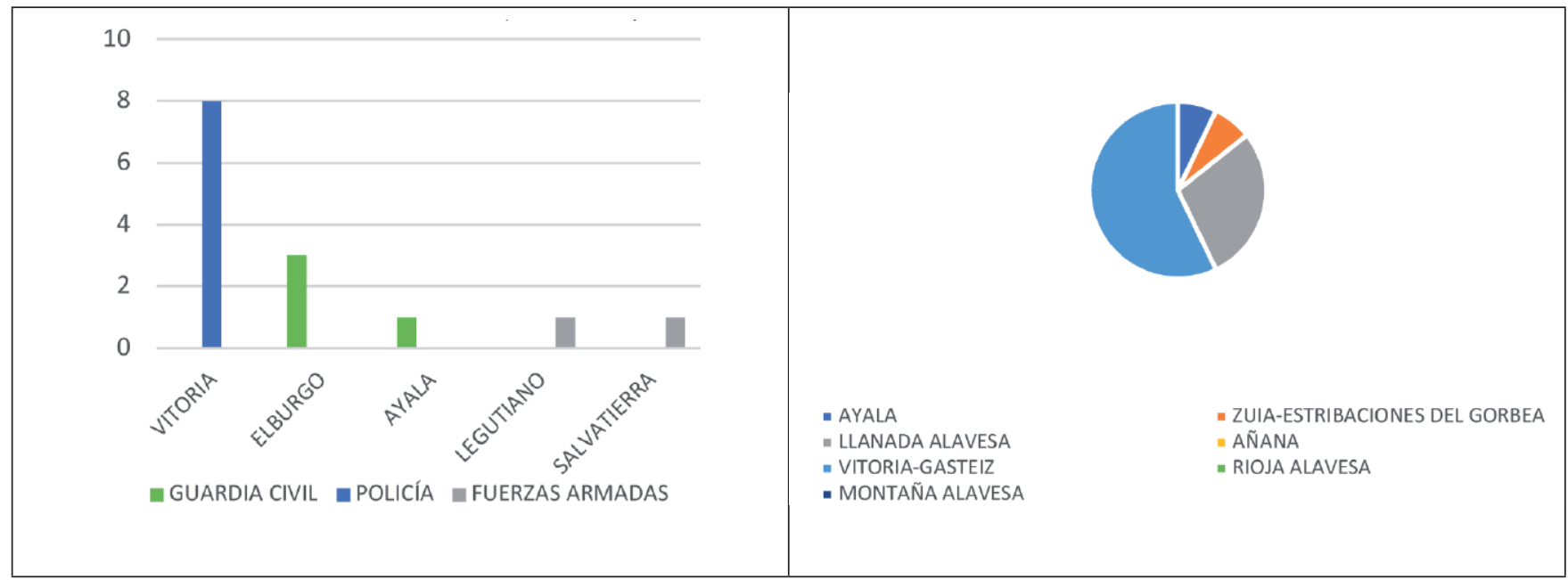

Gráfico 12. Víctimas mortales de las FCSE por municipio en Álava (1982-1994).
Gráfico 13. Porcentaje de víctimas de las FCSE por comarca en Álava. Fuente: Elaboración propia sobre los datos obtenidos de López Romo (2015)

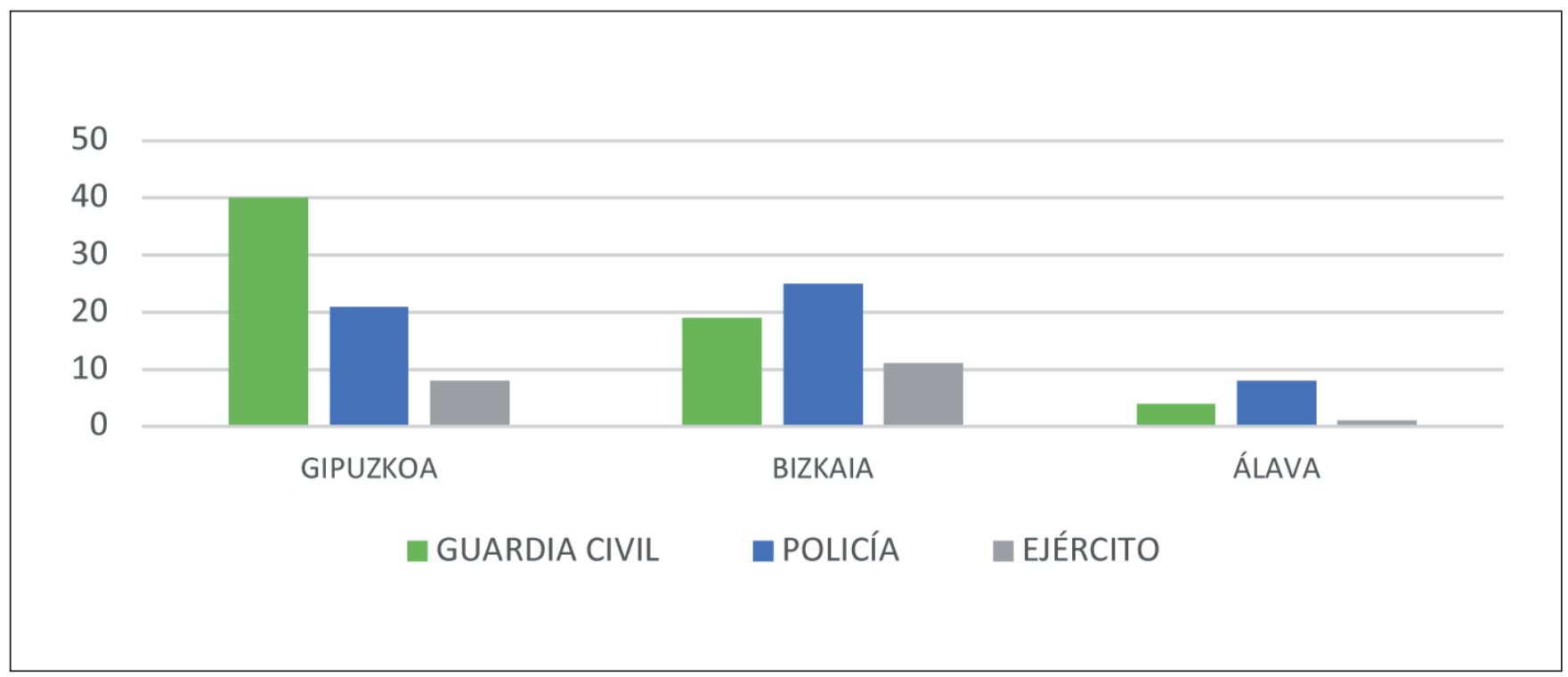

Gráfico 14. Víctimas mortales de las FCSE por territorio histórico. Fuente: Elaboración propia sobre los datos obtenidos de López Romo (2015).

Como se observa en los gráficos 15 y 16, las FCSE fueron uno de los colectivos más afectados por el terrorismo entre 1982 y 1994 (Company Alcañiz, 2016: 4). De hecho, si estos datos se ponen en perspectiva siguiendo los elaborados por López Romo (2015: 150-153), que ha cifrado en 914 las víctimas mortales causadas por el terrorismo endógeno en España (incluyendo las acciones perpetradas por grupos parapoliciales y de extrema derecha como el Batallón Vasco Español y GAL, entre otros), se puede concluir que 594 de esas 914 víctimas se produjeron sólo en el País Vasco entre 1968 y 2011. En el periodo de la guerra de desgaste, coincidente con el de la consolidación democrática, hubo 388 víctimas mortales, siendo casi la mitad (ex) miembros de las FCSE o personas con algún tipo de vínculo directo con los representantes de estos cuerpos de seguridad. Las cifras son, por tanto, altas si se hace hincapié en Euskadi en el periodo analizado: de esas 388 víctimas mortales, ETA y los CAA segaron la vida de 137 funcionarios públicos, de las que solo 6 fueron víctimas de las acciones de este último grupo. 


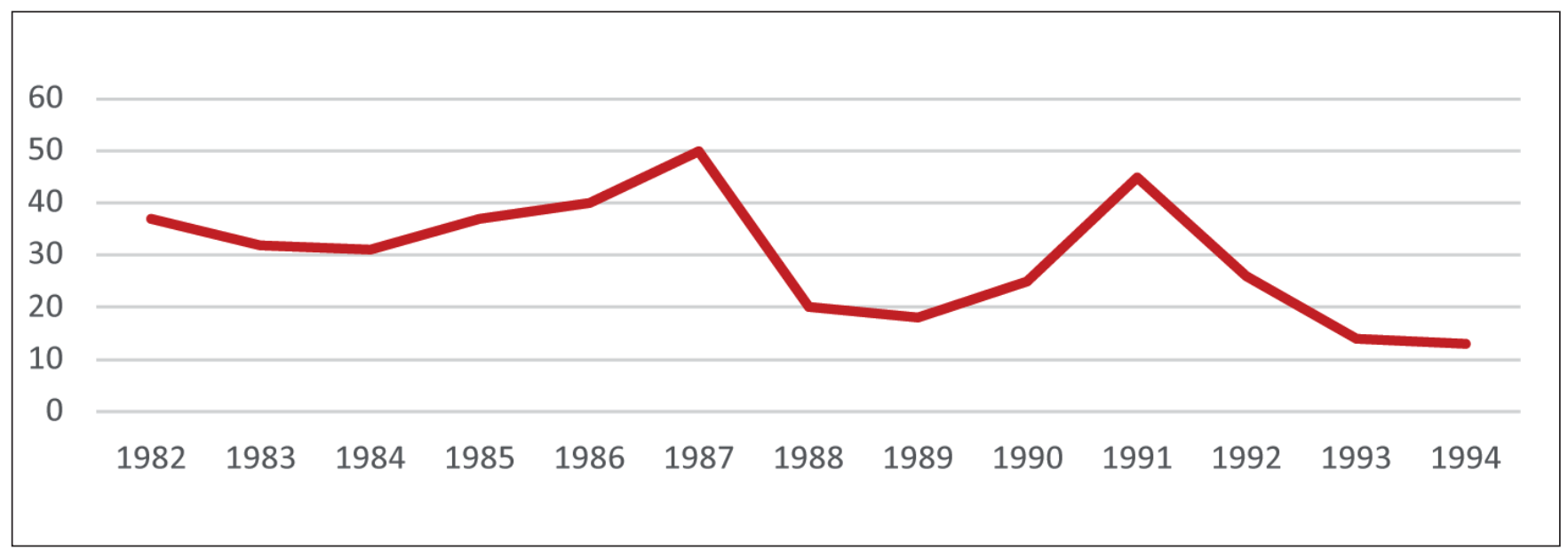

Gráfico 15. $\mathrm{N}^{\mathrm{o}}$ de víctimas mortales de ETA en toda España. Fuente: Elaboración propia sobre los datos obtenidos de López Romo (2015).

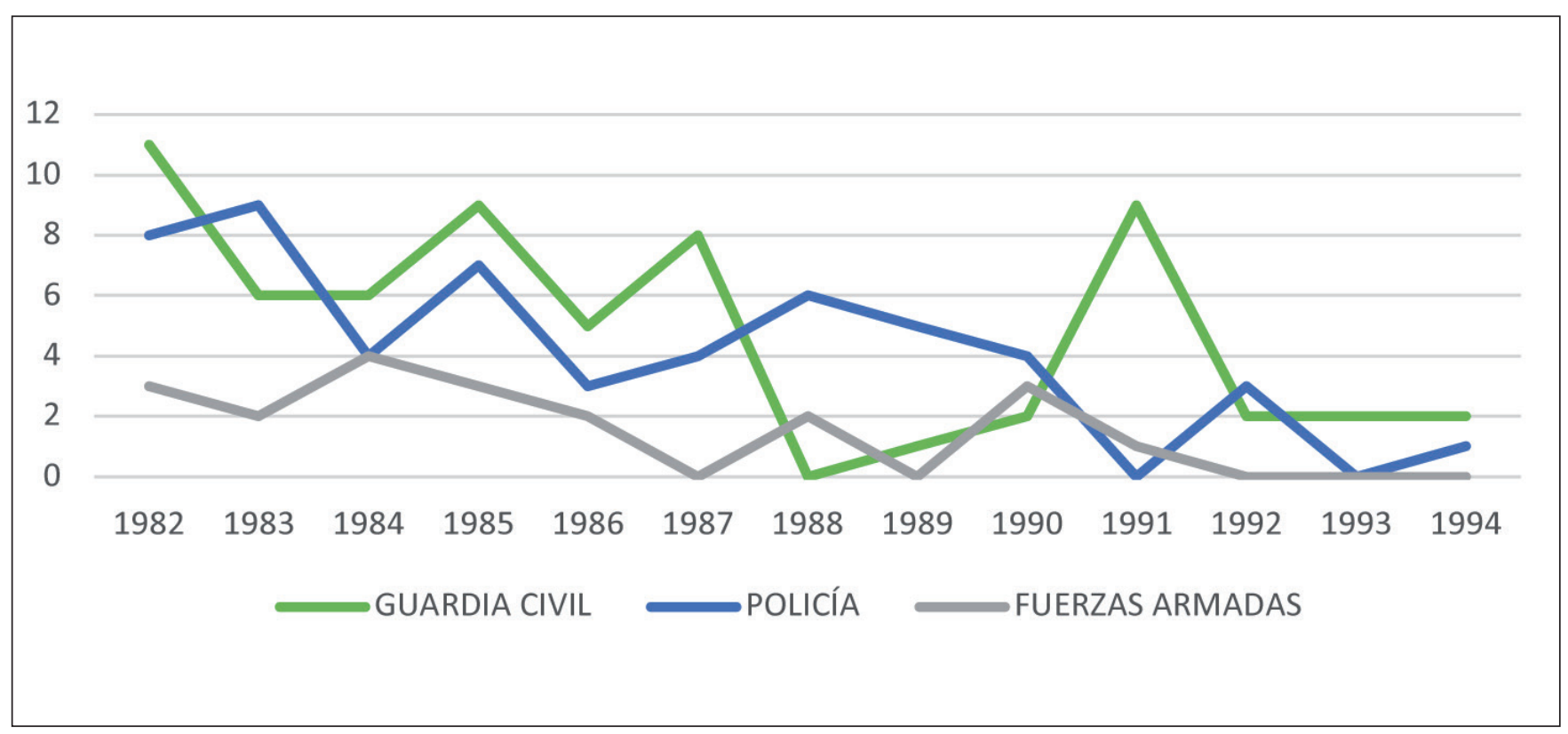

Gráfico 16. № de víctimas mortales de las FCSE en Euskadi por año. Fuente: Elaboración propia sobre los datos obtenidos de López Romo (2015).

Entre 1982 y 1994, sólo en Euskadi fueron asesinados 63 agentes de la Guardia Civil, siendo Gipuzkoa la provincia donde se produjo el mayor índice de víctimas mortales del Instituto Armado. Una diferencia notable en lo que respecta a la Policía que, si bien en Gipuzkoa sufrió un elevado número de atentados, con 21 víctimas mortales a lo largo de la guerra de desgaste, la provincia más mortífera para los agentes de la Policía fue Bizkaia con 25 agentes fallecidos. En el viejo señorío, las Fuerzas Armadas también fueron duramente azotadas, pues fue aquí donde se concentró el mayor número de asesinatos contra militares. No obstante, el mayor porcentaje de vidas de altos cargos militares segadas por ETA y los CAA se produjo en Gipuzkoa. En Álava, en cambio, fue donde se produjo el número más bajo de víctimas mortales de las FCSE durante el periodo estudiado con un total de 20 bajas. Por tanto, si se atiende a la distribución geográfica de los atentados se puede concluir que la mayoría se localizó en las provincias vascas marítimas, en zonas urbanas, siendo Álava el territorio menos afectado, como se puede observar en el gráfico 17. 


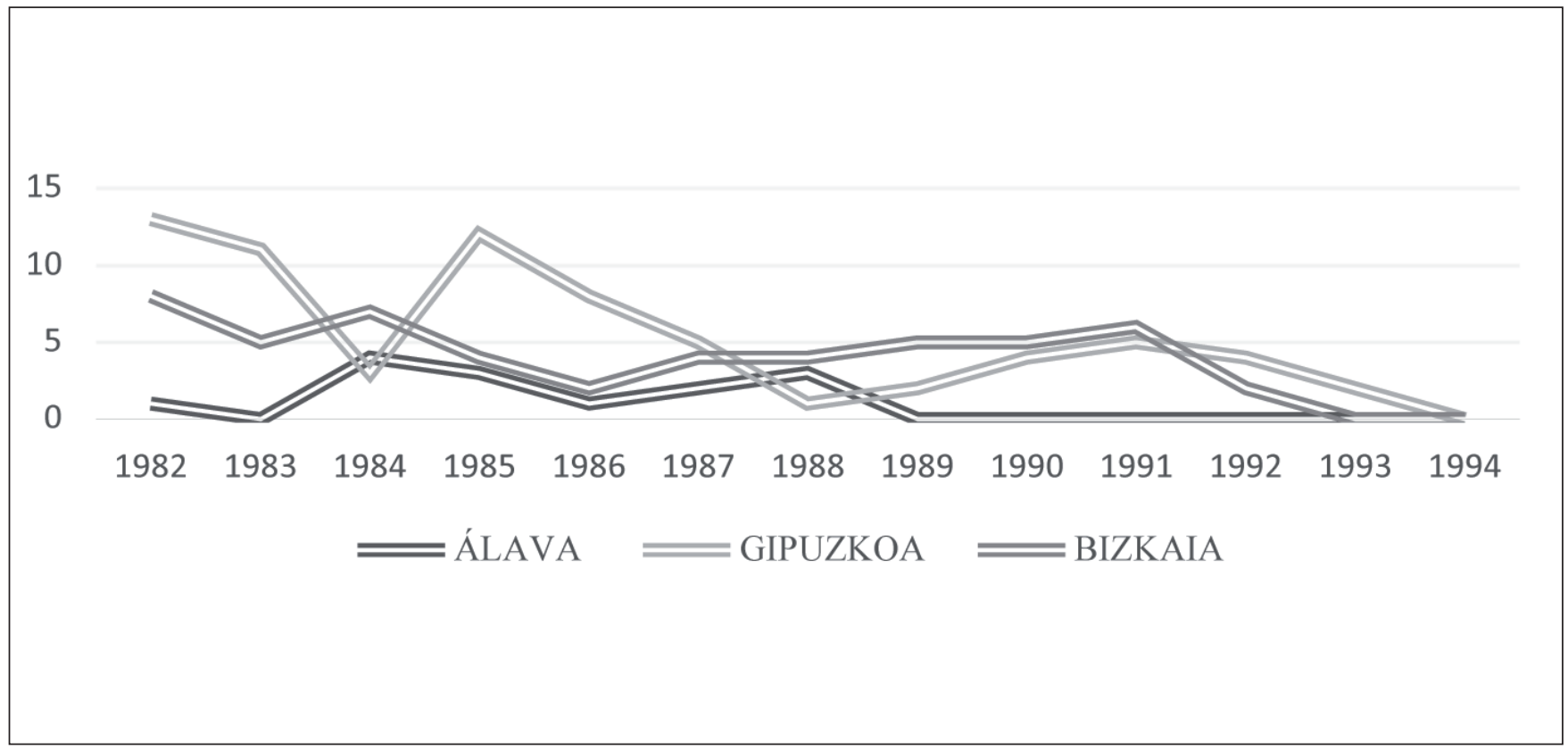

Gráfico 17. $\mathrm{N}^{\circ}$ de víctimas mortales de las FCSE por provincias de las FCSE por provincias. Fuente: Elaboración propia sobre los datos obtenidos de López Romo (2015).

Por otro lado, el análisis de la procedencia de las víctimas ofrece datos significativos sobre su perfil: la mayoría tanto de agentes de la Guardia Civil como de la Policía fallecidos en atentado a manos de los grupos terroristas citados en este trabajo procedieron, en primer lugar, de Castilla y León; en segundo, de Andalucía; y, en tercero, de Galicia. Estas tres comunidades autónomas son el origen del 50 por ciento del total de víctimas de las FCSE fallecidos por actos de violencia terrorista. Estos datos, por tanto, refuerzan la idea ya apuntada de que los miembros de la Guardia Civil y de la Policía fueron un blanco preferente del terrorismo durante toda la Transición y la Democracia.

En cambio, la situación de los militares fue distinta. Si se observa el gráfico 18 se comprueba que la mayoría de los militares que fueron víctimas mortales del terrorismo nacieron en el País Vasco (en total seis), seguido de cerca por Andalucía y Galicia. Por tanto, el 30 por ciento de los militares asesinados por ETA y los CAA entre 1982 y 1994 fueron naturales de Euskadi, siendo el resto de Andalucía, Galicia y Aragón, entre otras procedencias.

Igualmente, tomando como referencia las tres comunidades autónomas de procedencia con mayor número de víctimas de las FCSE (gráfico 19), resulta significativo (pero no extraño, pues eran las zonas más pobladas) que la mayoría de los agentes de la Guardia Civil procedentes de Castilla y León fallecieran en la comarca guipuzcoana de Donostialdea y en la vizcaína del Gran Bilbao. Lo mismo sucede con los oriundos de Andalucía, que fallecieron en su mayor parte en Donostialdea, mientras que en Bizkaia sólo hubo víctimas mortales en las zonas rurales de Busturialdea y Uribe Kosta. En el caso de los procedentes de Galicia y Extremadura hubo mayor disparidad comarcal, con cuatro víctimas en Bizkaia y dos en Álava, respectivamente. Si bien, como en el resto de los casos, Gipuzkoa continuó siendo el eje más virulento.

Con respecto a las víctimas que eran agentes de la Policía (gráfico 20), se constata que tanto en Gipuzkoa como en Bizkaia la mayoría de (ex)agentes fallecidos por violencia terrorista fueron de procedencia castellanoleonesa, seguidos muy de cerca por otros de origen andaluz. Sorprenden, empero, algunos datos de interés. En primer lugar, en Bizkaia, después de los castellanoleoneses, los agentes de origen gallego fueron los más azotados, incluso por delante de los andaluces. Y, en segundo, resulta significativo que el cuarto origen de policías más azotado por el terrorismo sea precisamente el País Vasco, del que hay cuatro víctimas (dos en cada una) tanto en Bizkaia como en Álava. 


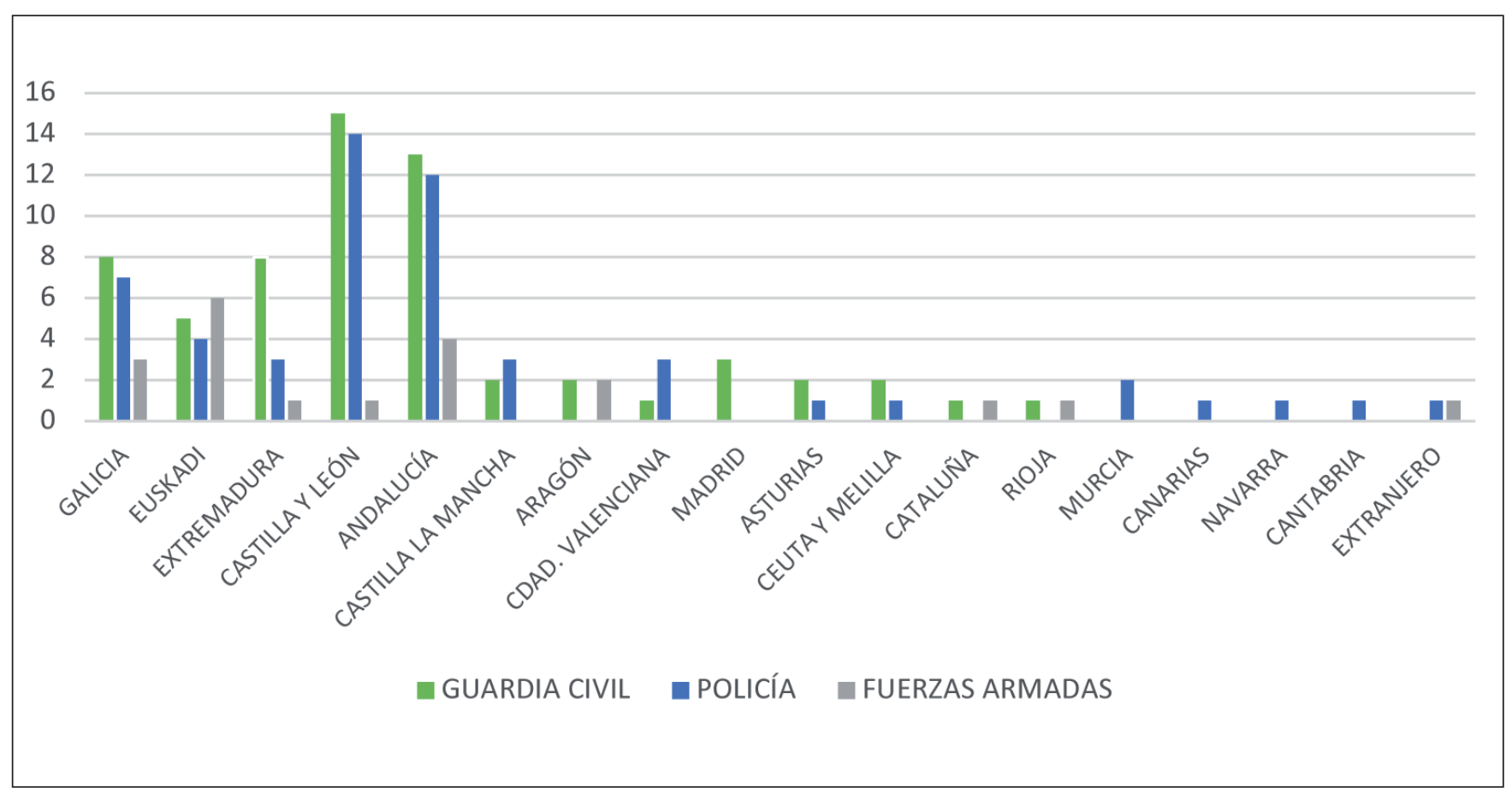

Gráfico 18. Víctimas de las FCSE por procedencia y cuerpo de servicio. Fuente: Elaboración propia sobre los datos obtenidos de Mapa del Terror de COVITE.

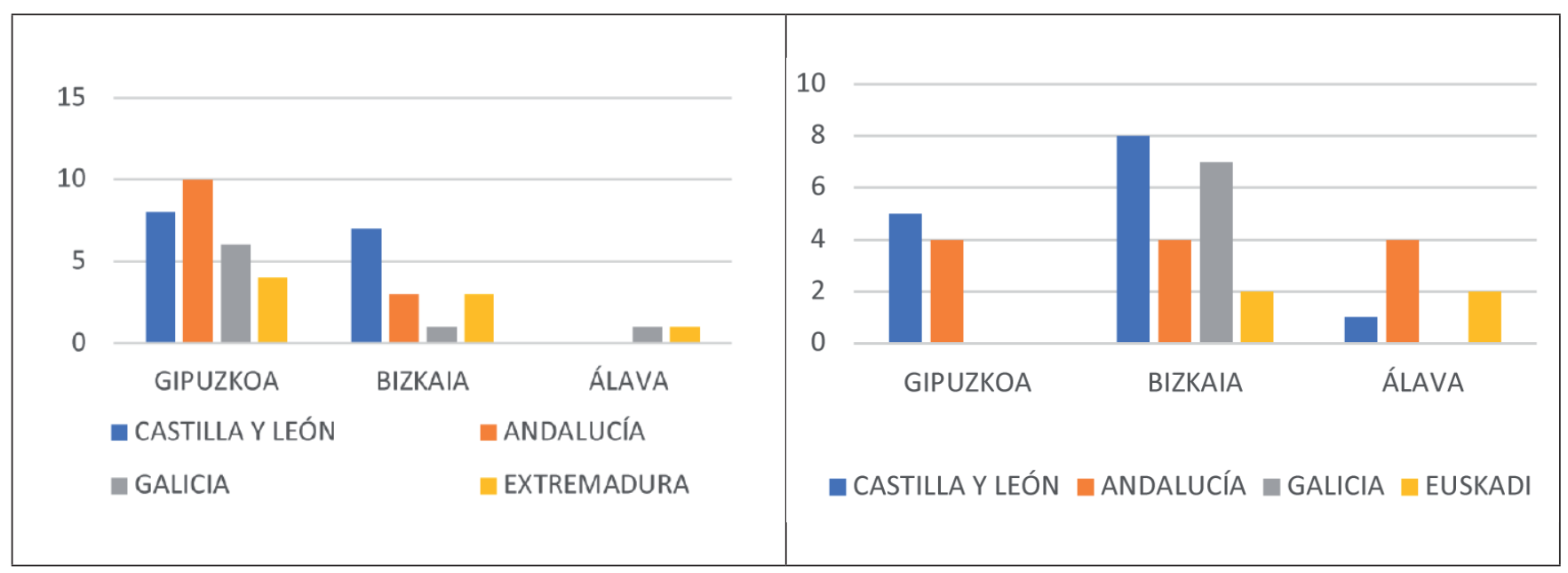

Gráfico 19. Víctimas del terrorismo (guardias civiles) por provincia, según origen.

Gráfico 20. Víctimas del terrorismo (policías) por provincia, según origen (1982-1994). Fuente: Elaboración propia sobre los datos obtenidos de López Romo (2015) y del Mapa del Terror de COVITE.

\section{DISCUSIÓN Y CONCLUSIONES}

Como se ha visto a lo largo del artículo, el colectivo de las FCSE fue el más afectado durante la etapa de consolidación democrática. De hecho, tras haber puesto en perspectiva los datos aquí trabajados, se ha observado que casi el 65 por ciento del total de las víctimas mortales del terrorismo entre 1968 y 2011 se produjeron sólo en el País Vasco. Durante el periodo aquí estudiado, hubo 388 víctimas mortales, siendo casi la mitad (ex)miembros de las FCSE o personas vinculadas con estos cuerpos de seguridad. Las cifras son elevadas para el periodo analizado en el País Vasco, pues aquí el terrorismo segó la vida de 137 personas. 


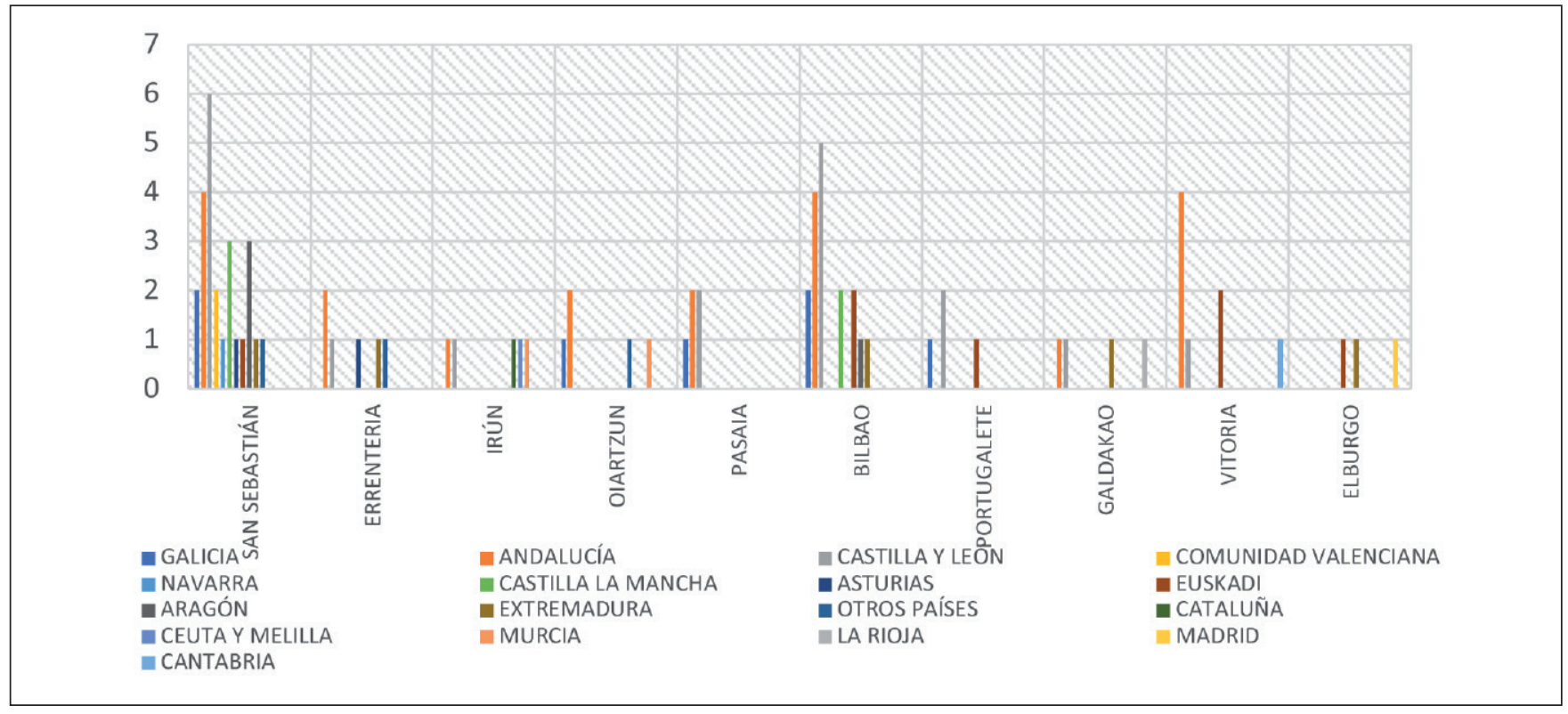

Gráfico 21. Víctimas de las FCSE por procedencia en los municipios vascos con más asesinatos. Fuente: Elaboración propia sobre los datos obtenidos de López Romo (2015) y del Mapa del Terror de COVITE

Durante el periodo de consolidación democrática, en el País Vasco fueron asesinados 63 guardias civiles, siendo Gipuzkoa el territorio de mayor índice de víctimas mortales de la Benemérita. En este mismo territorio, la Policía experimentó un elevado número de atentados, con 21 víctimas mortales a lo largo de la guerra de desgaste. Sin embargo, la provincia más mortífera para la Policía fue Bizkaia con 25 agentes fallecidos. Aquí, los militares también fueron brutalmente asesinados, concentrando este territorio el mayor número de víctimas de esta categoría. Pero, como se ha visto, el mayor porcentaje de vidas de altos cargos militares segadas por el terrorismo se produjo en Gipuzkoa. La situación de Álava, empero, fue distinta. En esta provincia hubo el número más bajo de víctimas mortales de las FCSE durante la cronología aquí manejada, con 20 bajas. Por consiguiente, atendiendo a la distribución geográfica de los atentados se puede afirmar que el mayor número de ellos se concentró en Bizkaia y Gipuzkoa, principalmente en sus zonas urbanas, mientras que Álava fue el territorio menos afectado.

En lo que concierne al ámbito de las víctimas heridas por ETA, la distribución es bastante similar a la de las mortales. Según los datos aportados por Jiménez y Marrodán (2019, p. 119) la mayoría de las víctimas heridas por la organización nacionalista vasca radical en toda España, que se concentran en las décadas de 1970 a 2000 (años de su máxima actividad) se produjeron en Gipuzkoa, Bizkaia, Madrid y Navarra. Igualmente, atendiendo a los totales, según explican estos autores, la Guardia Civil fue el colectivo de las FCSE más golpeado por el terrorismo de acuerdo con la categoría de heridos reconocidos por el Estado, seguido de la Policía Nacional y las Fuerzas Armadas. Esta naturaleza victimológica y este orden coinciden plenamente con lo trabajado en este artículo, donde los tres cuerpos señalados fueron igualmente los más azotados.

Pero la riqueza de los datos de Jiménez y Marrodán es aún mayor si se cruzan con los proporcionados en esta investigación sobre las víctimas mortales de las FCSE entre 1982 y 1994. De hecho, se observa que durante estos años los heridos por ETA fueron en torno a un 35 por ciento del total de víctimas causadas a lo largo de toda su historia de actividad terrorista, es decir, entre 1959 y 2011 (Jiménez \& Morradán, 2019, p. 151). Ahora bien, debe tenerse en cuenta que, por ejemplo, en 1987 hubo un altísimo número de heridos, fruto de dos atentados contra las FCSE y la sociedad civil, que se produjeron ese año fuera del País Vasco y que incrementan ostensiblemente el número de víctimas: la bomba de Hipercor de junio en Barcelona y la de la Casa Cuartel de la Guardia Civil de diciembre en Zaragoza.

En este sentido, se entiende, por ejemplo, que al igual que la Guardia Civil fue el colectivo con el mayor número de fallecidos a manos de la violencia de ETA, también concentró el mayor número de heridos. Las décadas de 1980 y 1990, en las que se ubica cronológicamente este artículo, concentran más del 60 por ciento de 
heridos de este cuerpo policial siendo, una vez más, Gipuzkoa el territorio más afectado. Para estas mismas décadas, la Policía Nacional concentra más del 70 por ciento del total de heridos de esta fuerza de seguridad en toda la trayectoria mortífera de ETA y CAA. Bizkaia es la provincia con más víctimas heridas de la Policía Nacional, a lo que se suma, como se aporta en este artículo, que el territorio vizcaíno fue el que tuvo más víctimas mortales de esta naturaleza en el periodo estudiado. Igualmente sucede con las Fuerzas Armadas, que concentran el 98 por ciento de heridos durante las décadas señaladas. Si bien, en este apartado las provincias más azotadas son Madrid y Zaragoza, seguidas en tercer y cuarto lugar por Gipuzkoa y Bizkaia que, entre las dos, concentran el 28 por ciento de heridos de esta tipología (Jiménez \& Morradán, 2019, p. 161).

De acuerdo con su procedencia, como se ha analizado en este trabajo, Castilla y León, Andalucía, Galicia, Extremadura y País Vasco fueron en este orden las comunidades autónomas de origen de la mayor parte de las víctimas mortales de las FCSE en Euskadi. De hecho, la mayoría de los agentes de la Guardia Civil y de la Policía, oriundos de estos lugares, fallecieron en Gipuzkoa y Bizkaia, los territorios más poblados. Pero más concretamente en Bilbao y San Sebastián (también en Vitoria): las capitales de provincia. Estas ciudades, junto con otros municipios de la conurbación donostiarra y vizcaína, ubicados en las comarcas de Donostialdea, Bajo Bidasoa y Gran Bilbao, fueron los más afectados concentrando más de tres cuartas partes de los atentados mortales contra las FCSE, lo que evidencia que, efectivamente, el terrorismo de ETA y los CAA fue entre 1982 y 1994 un fenómeno fundamentalmente urbano.

Por otro lado, continúa habiendo interrogantes que se desprenden de este estudio que no han podido ser respondidos. Uno de ellos es ¿por qué la mayor parte de los miembros de la Guardia Civil y la Policía fallecidos en atentado terrorista en Euskadi durante estos años fueron naturales de Castilla y León y Andalucía y, en cambio, en el caso de los militares, hubo un alto porcentaje nacido en el País Vasco? Esta y otras preguntas que han quedado irresolutas tienen su justificación: en primer lugar, no hay suficientes estudios al respecto que permitan lanzar siquiera una hipótesis plausible; $y$, en segundo, es muy complicado argumentar por qué murieron en Euskadi más miembros de un origen que de otro sin caer en reduccionismos simplistas.

Y es que el hecho de que un importante número de militares víctimas de ETA nacieran en el País Vasco y que en el caso de la Guardia Civil los fallecidos procedieran de Castilla-Léon, Andalucía y Galicia, responde en la mayor parte de las ocasiones a una situación meramente circunstancial: ETA les asesinó por su rango o pertenencia a las FCSE y ser, por consiguiente, representantes del Estado, pero no hay evidencias de que se detuviera a analizar si sus víctimas habían nacido en el País Vasco o en otros territorios, como prueba que los militares, la mayor parte de origen vasco, fueran el cuerpo más azotado.

En este último caso, que fueran naturales de Euskadi y que estos tuvieran una red de sociabilidades asentada puede que fuera un elemento coadyuvante para que ETA tuviera más facilidades para acceder a ellos, ya que tal circunstancia pudo generarles una sensación de falsa seguridad. Ahora bien, ETA pudo poner a los no nativos en su punto de mira simplemente por su acento (andaluz, gallego, castellano o extremeño) como ya sucedió con los tres jóvenes gallegos que fueron asesinados por ETA en 1973 en San Juan de Luz tras confundirlos con Policías (Rodríguez Fouz, 1998, p. 146). Debido a su origen, ETA pudo tener más facilidades para identificarles, sobre todo, en los municipios medianos y pequeños de la geografía vasca. Pero cabe tener en cuenta que la organización terrorista no pudo poner en su punto de mira a los miles de emigrantes que acudieron a Euskadi entre las décadas de 1960 y 1980 para trabajar en la industria (Galdos, 1985).

La inmigración de los años 60 y 70 a Euskadi fue efectivamente extremeña, gallega, andaluza y castellanoleonesa (Iraola, Mateos \& Zabalo, 2011). Sin embargo, esto no responde a que los miembros de las FCSE tuvieran que ser igualmente de ese origen. Lo que quizá expliqué su procedencia es que las FCSE encontraron en las citadas comunidades "expulsoras de población" un caladero de reclutamiento. En una época de crisis económica como la de finales de la década de 1970 formar parte de un cuerpo policial como los indicados ofrecía una oportunidad de vida, de mejora y de ascenso social, aún a riesgo de que su salida se produjera a un territorio ulsterizado y conflictivo como era la Euskadi de la época.

Por último, cabe traer a colación la respuesta social y política de la sociedad vasca ante el terrorismo y, especialmente, en lo que respecta a las FCSE. Las reacciones de los consistorios municipales, tanto del equipo de gobierno como de los representantes en pleno, fue muy dispar. En los primeros años de la década de 1980 , las condenas fueron minoritarias y muy puntuales en las capitales, pero en localidades guipuzcoanas 
de tamaño medio como Errenteria e Irún, lugares muy polarizados social y políticamente, los partidos constitucionalistas y nacionalistas moderados trataron casi siempre de llevar a pleno los atentados terroristas, dejando al margen la condición social, política y laboral de la víctima.

De la mitad de la década de 1980 en adelante hubo un aumento significativo del número de mociones de condena de las acciones de ETA llevadas a los plenos de los ayuntamientos vascos. Fue un hecho especialmente notorio en los consistorios vizcaínos y guipuzcoanos, dos de los territorios más afectados por el terrorismo. Sin embargo, estos actos de condena precisaron de una serie de requisitos en lugares emblemáticos como Bilbao y San Sebastián. Aquí se precisó de una combinación muy concreta de elementos como los siguientes: avecindamiento de la víctima en el municipio, desarrollo del atentado dentro de los límites fronterizos de la localidad, notoriedad pública de la víctima y consternación social derivada del asesinato. Aunque los miembros de las FCSE no siempre cumplieron con estos requisitos, los partidos no nacionalistas se encargaron de llevarlas a pleno solicitando previamente una sesión extraordinaria, tales fueron los casos del asesinato del coronel Enríquez García en el barrio bilbaíno de San Ignacio o del capitán de farmacia Alberto Martín Barrios, cuyo cuerpo sin vida apareció en una caseta del cruce de El Gallo, situado al este del municipio vizcaíno de Galdakao, amordazado, amoratado y con un disparo en la sien. Ambos casos fueron elevados a las corporaciones municipales de Bilbao y San Sebastián por parte de ediles de UCD y del PSEPSOE (AMA Bilbao, 28-10-1983 y AMA San Sebastián, 16-12-1983).

Tras la firma del acuerdo para la normalización y pacificación de Euskadi o Pacto de Ajuria Enea en 1988, el posicionamiento de los ayuntamientos contra las acciones terroristas fue mucho más patente. Las condenas se reprodujeron en localidades con un especial peso económico y poblacional como las guipuzcoanas Pasaia e Irún o la vizcaína Santurtzi. Aunque HB jugó un importante papel en estos y otros consistorios (en Pasaia, dirigieron el ayuntamiento a partir de 1991), las mociones salieron adelante por la convicción y tenacidad de los partidos políticos firmantes del acuerdo citado. Ahora bien, hubo ayuntamientos que no se pronunciaron, que omitieron o desoyeron los atentados que ETA había cometido en sus localidades (AMA Irún, 24-11-1984 y AMA Pasaia, 9-4-1990).

En la guipuzcoana Oiartzun, muy próxima a San Sebastián, se produjo un caso singular. La corporación municipal utilizó todo tipo de circunloquios para no condenar en 1982 el asesinato de José Fragoso, agente de la Guardia Civil de Aduanas en el puerto de Pasaia, que fue disparado a quemarropa cuando se dirigía a su domicilio en el barrio oyarsonense de Larzabal. En cambio, dedicó una especial atención a las detenciones realizadas por la Guardia Civil tras este y otros asesinatos (AMA Oiartzun, 25-2-1982).

No fue la única corporación en no pronunciarse. En capitales de provincia como Bilbao y San Sebastián hubo un acuerdo tácito de dejar fuera de pleno "temas extramunicipales", aunque hubo referencias puntuales a algunos actos terroristas. En otros municipios como Galdakao y Ondarroa no hubo siquiera ademán de llevarlo a pleno. Este tipo de gestos (o la ausencia de ellos) contribuyeron a reducir la visibilidad de las acciones terroristas contra los miembros de las FCSE, relegando a la víctima al anonimato y a su cosificación. En Errenteria, por ejemplo, el PSE-PSOE presentó una moción de condena por el asesinato del guardia civil Modesto Martín que fue respondida del siguiente modo por el público «que se haya muerto un tío de éstos, al pueblo no le afecta para nada» (AMA Errenteria, 18-3-1982).

HB contribuyó a este tipo de argumentario, que se mostró indiferente y combativa y que trató de imponer su narrativa sobre el terrorismo. También la postura ambigua del nacionalismo vasco moderado y, por supuesto, la falta de empatía del común de la sociedad civil vasca. Ese mutismo social y político retroalimentó la violencia terrorista. Un discurso que maleó el imaginario social mucho más de lo que a juicio de HB pudo realizar «la violencia uniformada» (Portela, 2016, p. 65).

En conclusión, el objetivo de los terroristas fue tanto silenciar a las voces disidentes de la sociedad civil, que casi siempre ocuparon cargos públicos o fueron empresarios no nacionalistas, como el asesinato de los miembros de las FCSE por considerarles un objetivo a batir debido a su cargo como representantes del Estado. Hasta finales de la década de 1980 en que hubo un cambio significativo en la actitud hacia el terrorismo, buena parte de la sociedad vasca toleró indiscriminadamente las acciones terroristas (fundamentalmente atentados y amenazas) cometidas contra las FCSE debido al mantra repetido desde diferentes sectores nacionalistas radicales de que tras la muerte de Franco nada había cambiado, que la democracia era una 
dictadura encubierta y que las FCSE continuaban actuando con la misma contundencia represiva contra el pueblo vasco. Este imaginario tuvo un importante peso en la actitud de indiferencia de la sociedad civil vasca hacia los desmanes desproporcionados cometidos por los terroristas, lo que influyó sobremanera en la demonización de las FCSE, el vacío sufrido por sus miembros y familiares y que ETA no necesitara «justificar moralmente sus acciones» (Aranzadi, Juaristi \& Unzueta, 1994, p. 197).

\section{Financiación}

Este artículo se ha realizado dentro del Grupo de Investigación GIR03. Humanidades y Ciencias sociales en la Era digital y Tecnológica que coordino en la Universidad Isabel I y en el marco de la línea de investigación "L.06. Política, Economía, Sociedad y Memoria: El Estado en los siglos XIX a XXI" de la que soy investigador responsable. También es resultado tanto del proyecto PGC2018-094133-B-100 (MCIU/AEI/FEDER, UE) que dirige Coro Rubio Pobes en la UPV-EHU como del proyecto Historia y memoria del Terrorismo en el País Vasco coordinado por José Antonio Pérez en el marco de las investigaciones impulsadas por el Centro para la Memoria de las Víctimas del Terrorismo.

\section{Agradecimientos}

Como autor de este trabajo tengo una deuda pendiente con todas las personas que de algún modo han sido testigos de su elaboración o que me han animado a su realización. Me gustaría agradecer expresamente el apoyo y sugerencias a Antonio Gavira Narváez, Sergio Cañas Díez, Santiago de Pablo Contreras, Coro Rubio Pobes, Gaizka Fernández Soldevilla, Jerónimo Ríos Sierra y José Antonio Pérez. Muy especialmente, a los miembros del grupo de investigación «GIR-03 Humanidades y Ciencias Sociales en la Era digital y tecnológica» de la Universidad Isabel I, en especial, a la línea «Política, Economía, Sociedad y Memoria: el Estado de los siglos XIX al XXI».

\section{Declaración responsable y conflicto de intereses}

El trabajo remitido es un documento original y no ha sido publicado con anterioridad, total o parcialmente por otros autores. El firmante de este artículo es públicamente responsable de sus contenidos y elaboración y no ha incurrido en fraude científico o plagio. Si se demostrara lo contrario, el autor de este trabajo aceptará las medidas disciplinarias o sancionadoras que correspondan. Por otro lado, el firmante de este texto declara no tener ningún conflicto de intereses ni total, ni parcial, ni potencial en relación a la publicación de este artículo. Si bien, conviene señalar que su contenido, en el que las víctimas del terrorismo tienen un papel relevante, ha sido tratado desde la rigurosidad académica, atendiendo la consideración social de la víctima.

\section{REFERENCIAS}

Abella-Uyarra, A. (2016). Dos investigaciones sobre la victimización terrorista. Sistematización de testimonios y estudio de caso único. E-Eguzkilore: Revista electrónica de Ciencias Criminológicas, 1, 1-47.

Águila, M. Á. (2011). Las treguas de ETA desde una perspectiva comparada. Visión Libros.

En L.R. Aizpeolea (2013) Los entresijos del final de ETA. Un intento de recuperar una historia manipulada. Catarata.

Alonso, R. (2018). La derrota del vencedor. La política antiterrorista del final de ETA. Alianza.

Alonso, R., Domínguez, F. \& García-Rey, M. (2010). Vidas rotas. Historia de hombres, mujeres y niños víctimas de ETA. Espasa. Álvarez Bragado, E. (2018). El problema vasco en la transición democrática española (1975-1979) [Tesis doctoral inédita]. Universidad Complutense.

Angulo, G. (2018). La persecución de ETA a la derecha vasca. Almuzara

Aranzadi, J., Juaristi, J. \& Unzueta, P. (1994). Auto de terminación: (raza, nación y violencia en el País Vasco). El País-Aguilar. Arregi, J. (2015). El terror de ETA. La narrativa de las víctimas. Tecnos. 
Arrieta, L. (2015). ETA y la espiral de la violencia. Estrategias y víctimas. En M.P. Rodríguez (coord.) (pp. 21-52) Imágenes de la memoria: víctimas del dolor y la violencia terrorista. Biblioteca Nueva.

Avilés, J. (2010). El terrorismo en España: de ETA a Al Qaeda. Arco Libros.

Azcona, J. M. \& Re, M. (2009). La consideración de ETA y Brigadas Rojas de sus víctimas. Embrutecimiento e hipocresía de los terroristas. En R. Martín de la Guardia \& Pérez Sánchez, G. (coord.) (pp. 107-120). Los derechos humanos sesenta años después (1948-2008). Universidad de Valladolid.

Azurmendi, J. F. (2014). ETA. De principio a fin. Crónica documentada de un relato. Ttarttalo.

Azurmendi, J.F. (2012). PNV-ETA. Crónica oculta (1960-1979). Ttarttalo.

Baby, S. (2018). El mito de la transición pacífica. Violencia y política en España (1975-1982). Akal.

Batista, A. (2011). Adiós a las armas. Una crónica del final de ETA. Debate.

Buckley, N. (2020). Del sacrificio a la derrota. Historia del conflicto vasco a través de las emociones de los militantes de ETA. Siglo XXI. Calle, L. de la y Sánchez-Cuenca, I. (2004). La selección de víctimas en ETA. Revista Española de Ciencia Política, $10,53-79$.

Calleja, J. M. (1997). Contra la barbarie. Un alegato en favor de las víctimas de ETA. Temas de Hoy.

Calleja, J. M. (2005). Las víctimas del terrorismo de ETA. Historia, organización y su relejo en los medios de comunicación [Tesis doctoral]. Universidad Complutense.

Casquete, J. (2009). En el nombre de Euskal Herria: la religión política del nacionalismo vasco radical. Tecnos.

Castells, L. (2017). La sociedad vasca ante el terrorismo. Las ventanas cerradas (1977-2011). Historia y política: Ideas, procesos y movimientos sociales, 38, 347-382. https://doi.org/10.18042/hp.38.12

Cid Cebrián, M. (2013). Ante el final de ETA. La fuerza del perdón (1998-2013). Catarata.

Company Alcañiz, M. (2016). El estigma de las Fuerzas y Cuerpos de Seguridad víctimas del terrorismo en su victimización. Revista Electrónica de Ciencias Criminológicas, 1, 1-36.

Cuerda, A. (2016). El Derecho penal ante el fin de ETA. Tecnos.

De Pablo, S. (2017). Creadores de sombras. ETA y el nacionalismo vasco a través del cine. Tecnos.

De Pablo, S. (2019). Julio de 1959. El nacimiento de ETA. Historia Actual Online, 48, 45-59.

De Pablo, S., Mota Zurdo, D. \& López de Maturana, V. (2018). Testigo de cargo. La historia de ETA y sus víctimas en televisión. Beta. Domínguez, F. (1998a). De la negociación a la tregua: ¿el final de ETA? Taurus.

Domínguez, F. (1998b). ETA. Estrategia organizativa y actuaciones (1978-1992). Universidad del País Vasco.

Domínguez, F. (2003). Las raíces del miedo. Euskadi, una sociedad atemorizada. Aguilar.

Domínguez, F. (2011). Los años de plomo del terrorismo europeo y el caso español. En Azcona, J. M.; Re, M. y Azpiazu, M. D. (ed.). Sociedad del bienestar, vanguardias artísticas, terrorismo y contracultura. España-Italia (1960-1990). Dykinson, $175-194$. Domínguez, F. (2017). Las claves de la derrota de ETA, Informe del Centro Memorial de las Víctimas del Terrorismo, 3, 1-67. Domínguez, F. \& Fernández Soldevilla, G. (2018). Pardines. Cuando ETA empezó a matar, Tecnos.

Eguiguren, J. \& Rodríguez Aizpeolea, L. (2012). ETA las claves de la Paz. Confesiones del negociador. Aguilar.

Escrivá, A. (2012). Maldito el país que necesita héroes. Cómo los demócratas acabaron con ETA. Temas de Hoy.

Estebaranz, J. I. (2011). Tardofranquismo y transición: experiencias de autoorganización obrera en el País Vasco. Los Comandos Autónomos Anticapitalistas. Universidad del País Vasco.

Fernández Soldevilla, G. (2015). Mitos que matan. La narrativa del conflicto vasco, Ayer, 98, 213-240.

Fernández Soldevilla, G. (2016). La voluntad del gudari. Génesis y metástasis de la violencia de ETA. Tecnos.

Fernández Soldevilla, G. (2018d). Matar por la patria. Nacionalismo radical y violencia terrorista en España (1975-2016). En I. Sepúlveda (ed.) (pp. 293-326). Nación y nacionalismos en la España de las autonomías. Centro de Estudios Políticos y Constitucionales.

Fernández Soldevilla, G. (2021). Historia del terrorismo en España. De ETA al Dáesh. Cátedra.

Fernández Soldevilla, G. \& Jiménez, M. (2020). 1980. El terrorismo contra la transición. Tecnos.

Fernández Soldevilla, G. \& López Romo, G. (2012). Sangre, votos, manifestaciones: ETA y el nacionalismo vasco radical 19582011. Tecnos.

Fusi, J. P. (2012). Historia mínima de España, Turner.

Fusi, J.P. \& Pérez, J. A. (eds.) (2017). Euskadi 1960-2011. Dictadura, transición y democracia. Biblioteca Nueva.

Gago, E. \& Ríos, J. (2021). La lucha hablada. Conversaciones con ETA. Altamarea.

Galdos, R. El declinar de la inmigración y el crecimiento de la migración interior en el País Vasco: 1971-1981. Lurralde, 8, $183-188$ 
García Varela, P. (2019). Las mujeres víctimas mortales de ETA y grupos afines. Revista de Historia Actual, 16-17, 113-128 García Varela, P. (2020). ETA y la conspiración de la heroína. Catarata.

Garmendia, J. M. (1996). Historia de ETA. Haranburu.

González Calleja, E. (2012). El laboratorio del miedo. Una historia general del terrorismo. Crítica.

Granja, J.L., De Pablo, S. \& Rubio, C. (2020). Breve Historia de Euskadi. De los fueros a nuestros días. Debate.

Heredero, L. (2020). El final del terrorismo de ETA. Una visión desde el derecho. Revista General de Derecho Administrativo, 54.

Hidalgo, S. (2018). Los resistentes. Relato socialista de la violencia de ETA (1984-2011), Catarata.

Hidalgo, S. \& Comonte, A. (2020). Resistencia socialista en femenino. Violencia de ETA y mujeres del PSE desde la Transición hasta 2011. Catarata.

Hurtado Martínez, C. (1999). La inseguridad ciudadana de la Transición a la sociedad democrática. España (1977-1989). Ediciones de la Universidad de Castilla-La Mancha.

Iraola, I., Mateos, T. \& Zabalo, J. (2011). Discursos sobre la integración. La inmigración al País Vasco en los años 19501970. RIPS 10 (3), 115-130.

Izquierdo, J. M. \& Aizpeolea, L. M. R. (2017). El fin de ETA. Así derrotó la democracia al terror. Espasa.

Jáuregui, G. (1985). Ideología y estrategia política de ETA. Análisis de su evolución entre 1959 y 1968. Siglo XXI.

Jiménez, M. (2018a). Las primeras víctimas de ETA. En F. Domínguez \& G. Fernández (coord.) (271-309). Pardines: cuando ETA empezó a matar. Tecnos.

Jiménez, M. (2018b). El valor del testimonio. Aportaciones de las víctimas de ETA al relato y a la sensibilización de la sociedad [Tesis doctoral inédita]. Universidad de Navarra

Jiménez, M. (2019). Las víctimas del terrorismo en España e Irlanda del Norte. Dinámicas de selección durante los "años de plomo" y políticas de reparación. Arbor: Ciencia, pensamiento y cultural, vol. 195 (792), 1-12. https://doi. org/10.3989/arbor.2019.792n2012

Jiménez, M. \& Marrodán, J. (2019). Heridos y olvidados. Los supervivientes del terrorismo en España. La Esfera de los Libros.

Labiano, R. (2019). Las víctimas de ETA en el cine y la literatura. Realidad y representación de los damnificados por el terrorismo (1968-2018). Universidad de Navarra.

Labiano, R. \& Marrodán, J. (2018). La lucha policial contra ETA: los atentados que no se cometieron. En G. Fernández \& F. Domínguez (coord.) (231-270). Pardines. Cuando ETA empezó a matar. Tecnos.

Leonisio, R. (2013). Las víctimas del terrorismo en el discurso de los partidos políticos vasco: una aproximación cuantitativa (1980-2011), Revista de estudios políticos, n 161, 13-40.

Llera, F. J. (2013). ETA. Medio siglo de terrorismo y limpieza étnica en Euskadi. Sistema: revista de Ciencias Sociales, 231 , 3-46.

Llera, F. J. \& Leonisio, R. (2015). Los secuestros de ETA y sus organizaciones afines, 1970-1997. Una base de datos. Revista española de Ciencia Política, 37, 141-160.

Llera, F. J. \& Leonisio, R. (2017). La estrategia del miedo. ETA y la espiral de violencia en el País Vasco. Informe del Centro Memorial de las Víctimas del Terrorismo, 1, 9-55.

López Romo, R. (2012). Euskadi en duelo. La central nuclear de Lemoiz como símbolo de la transición vasca. Hariadna.

López Romo, R. (2015). Informe Foronda. Los efectos del terrorismo en la sociedad vasca. Catarata.

Marrodán, J., Araluce, G., García de Leániz, R. \& Jiménez, M. (2013). Relatos de plomo. Historia del terrorismo en Navarra 1960-86. Gobierno de Navarra.

Martín Peña, J. (2013). Amenazados de ETA en Euskadi: una aproximación al estudio científico de su victimación. Eguzkilore: Cuaderno del Instituto Vasco de Criminología, 27, 95-120.

Mees, L. (2020). The Basque Contention. Ethnicity, Politics, Violence. Routledge. https://doi.org/10.4324/9780429262586 Montero, M. (2018). El sueño de la libertad. Mosaico vasco de los años del terror. Ediciones Nobel.

Morán, S. (1996). La cooperación hispano-francesa en la lucha contra ETA. Universidad Complutense.

Moreno, I. (2019). Gestos frente al miedo. Manifestaciones contra el terrorismo en el País Vasco (1975-2013). Tecnos.

Muñoz Bolaños, R. (2021). El 23-Fy los otros golpes de Estado de la Transición. Espasa.

Muro, D. (2008). Ethnicity and Violence. The case of Radical Basque Nationalism. Routledge.

Murua, I. (2016). Un final para ETA. Crónica de un proceso inacabado. Ttarttalo.

Oneto, J. (2017). Operación: caza del gato. Hacia el final de ETA. Ibukku.

Ontoso, P. (2019). Con la Biblia y la Parabellum. Cuando la Iglesia vasca ponía una vela a Dios y otra al diablo. Península. 
Pérez, J.A. (dir.) (2021). Historia y memoria del terrorismo en el País Vasco. Confluencias.

Pérez, J.A. \& Carnicero, C. (2008). La radicalización de la violencia política durante la Transición en el País Vasco: los años de plomo, Historia del Presente, 12, 111-128.

Reinares, F. (2001). Patriotas de la muerte: por qué han militado en ETA y cuándo abandonan. Taurus.

Rivera, A. (2018). Naturaleza muerta. Usos del pasado en Euskadi después del terrorismo. PUZ.

Rivera, A. (2019). Nunca hubo dos bandos. Violencia política en el País Vasco, 1975-2011. Comares.

Rivera, A. \& Mateo, E. (eds.) (2020). Las narrativas del terrorismo. Cómo contamos, cómo transmitimos, cómo entendemos. Catarata.

Rodríguez Jiménez, J.L. (2017). Las víctimas en la literatura. ETA en la novela española. Cuadernos del Centro Memorial de las Víctimas del Terrorismo, 4, 74-96.

Rodríguez, M. P. (2017). Mujeres víctimas del dolor y la violencia terrorista. Biblioteca Nueva.

Rodríguez Fouz, M. (1998). Los duelos de la memoria: de la política en tiempos de oscuridad. Cuadernos de Alzate, 18, 123-150.

Sáez de la Fuente, I. (2017). Informe sobre la extorsión y la violencia de ETA contra el mundo empresarial. Secretaría General para la Paz y la Convivencia-Gobierno Vasco.

Sáez de la Fuente, I. \& Bilbao, G. (2020). Empresariado y extorsión. Las víctimas invisibles. En VV.AA. (pp. 66-81) Los empresarios y ETA. Una historia no contada. Nerea.

Sánchez Corbí, M. \& Simón, M. (2017). Historia de un desafío. Cinco décadas de lucha sin cuartel de la Guardia Civil contra ETA. Península.

Sánchez-Cuenca, I. (2001). ETA contra el Estado: las estrategias del terrorismo. Tusquets.

Sánchez-Cuenca, I. (2009). Análisis de la variación temporal en la letalidad de ETA. Revista Internacional de Sociología, 3, 609-629. https://doi.org/10.3989/ris.2008.03.24

Silva, L., Sánchez, M. \& Araluce, G. (2017). Sangre, sudor y paz. La Guardia Civil contra ETA. Península.

Sullivan, J. (1988). ETA and Basque Nationalism: The Fight for Euskadi 1890-1986. Routledge.

Ugarte, J. (coord.). La bolsa y la vida. La extorsión y la violencia de ETA contra el mundo empresarial. La Esfera de los Libros.

Uriarte, E. (2013). Tiempo de canallas. La Democracia ante el fin de ETA. Ikusager.

\section{FUENTES PRIMARIAS}

Archivo Municipal de Errenteria, Actas de Pleno, Gobierno Municipal.

Archivo Municipal de Bilbao, Actas de Pleno, Gobierno Municipal.

Archivo Municipal de San Sebastián, Actas de Pleno, Gobierno Municipal.

Archivo Municipal de Oiartzun, Actas de Pleno, Gobierno Municipal.

Archivo Municipal de Irún, Actas de Pleno, Gobierno Municipal.

Archivo Municipal de Pasaia, Actas de Pleno, Gobierno Municipal. 
ANEXOS

\section{LISTADO DE VÍCTIMAS DE LAS FCSE EN EUSKADI (1982-1994)}

Tabla 1. Víctimas de ETA miembros de las FCSE.

\begin{tabular}{|c|c|c|c|c|c|c|}
\hline Fecha & Nombre & Lugar & Procedencia & Años & Autor & Cuerpo \\
\hline $16-2-1982$ & Benjamín Fernández & San Sebastián & Galicia & 61 & ETA & GC \\
\hline $16-2-1982$ & José Fragoso & Oiartzun & Marruecos & 35 & ETA & GC \\
\hline 15-3-1982 & Modesto Martín & Errenteria & Extremadura & 41 & ETA & GC \\
\hline 22-3-1982 & Agustín Martínez & Sestao & Castilla y León & 27 & ETA & CNP \\
\hline 22-3-1982 & Alfonso Maside & Sestao & Galicia & 26 & ETA & CNP \\
\hline $26-3-1982$ & Antonio Gómez & San Sebastián & Andalucía & 24 & CAA & CNP \\
\hline $2-5-1982$ & Antonio Pablo Fernández & Ondarroa & Extremadura & 29 & ETA & GC \\
\hline 3-6-1982 & Daniel Enríquez & Bilbao & Castilla y León & 64 & ETA & FA \\
\hline $13-6-1982$ & José Luis Fernández & Pasaia & Galicia & 25 & ETA & $\mathrm{GC}$ \\
\hline 25-8-1982 & Miguel Garrido & Munguía & Andalucía & 22 & ETA & $\mathrm{GC}$ \\
\hline 25-8-1982 & Vicente Gómez & Munguía & Andalucía & 26 & ETA & $\mathrm{GC}$ \\
\hline 14-9-1982 & Jesús Ordóñez & Errenteria & Andalucía & 25 & ETA & CNP \\
\hline 14-9-1982 & Juan Seronero & Errenteria & Asturias & 35 & ETA & CNP \\
\hline 14-9-1982 & Alfonso López & Errenteria & Argentina & 30 & ETA & CNP \\
\hline 14-9-1982 & Antonio Cedillo & Errenteria & Andalucía & 29 & ETA & CNP \\
\hline 22-9-1982 & Emilio Fernández & Erandio & Galicia & 48 & ETA & FA \\
\hline 9-10-1982 & José Jiménez & Irún & Cataluña & 67 & ETA & GC \\
\hline 21-10-1982 & César Uceda & Bilbao & Andalucía & 47 & ETA & FA \\
\hline 31-10-1982 & Francisco González & Vitoria & Andalucía & 24 & ETA & CNP \\
\hline 12-12-1982 & Juan Ramón Joya & Tolosa & Melilla & 26 & ETA & $\mathrm{GC}$ \\
\hline 29-12-1982 & Juan Manuel García & Irún & Castilla y León & 48 & ETA & $\mathrm{GC}$ \\
\hline 29-12-1982 & Manuel López & Irún & Andalucía & 22 & ETA & $\mathrm{GC}$ \\
\hline $2-2-1983$ & Miguel Mateo & Ordizia & Comunidad Valenciana & 24 & ETA & GC \\
\hline 25-3-1983 & Ramón Ezequiel Martínez & Oiartzun & Murcia & 33 & CAA & CNP \\
\hline 27-3-1983 & Aniano Sutil & San Sebastián & Castilla y León & 26 & ETA & CNP \\
\hline $4-5-1983$ & Julio Segarra & Bilbao & Castilla La Mancha & 50 & ETA & CNP \\
\hline 4-5-1983 & Pedro Barquero & Bilbao & Andalucía & 30 & ETA & CNP \\
\hline
\end{tabular}




\begin{tabular}{|c|c|c|c|c|c|c|}
\hline Fecha & Nombre & Lugar & Procedencia & Años & Autor & Cuerpo \\
\hline 22-6-1983 & Juan Maldonado & Pasaia & Andalucía & 42 & ETA & GC \\
\hline 23-6-1983 & Emilio Juan Casanova & San Sebastián & Comunidad Valenciana & 29 & CAA & CNP \\
\hline 13-7-1983 & Manuel Francisco García & Sopela & Galicia & 26 & ETA & CNP \\
\hline 31-7-1983 & Rafael Gil & Getaria & Extremadura & 30 & CAA & GC \\
\hline 31-7-1983 & Enrique Rúa & Getaria & Galicia & 27 & CAA & GC \\
\hline $16-9-1983$ & Pablo Sánchez & Urnieta & Extremadura & 24 & ETA & CNP \\
\hline 3-10-1983 & Manuel Benito & Portugalete & Castilla y León & 36 & ETA & CNP \\
\hline 5-10-1983 & Ángel Flores & Errenteria & Castilla y León & 44 & ETA & GC \\
\hline 15-10-1983 & José Reyes Corchado & Oñati & Extremadura & 28 & ETA & GC \\
\hline 19-10-1983 & Alberto Martín & Galdakao & Euskadi & 39 & ETA & FA \\
\hline 12-11-1983 & Antonio de Vicente & Bermeo & Galicia & 52 & ETA & FA \\
\hline 15-12-1983 & Eduardo Navarro & San Sebastián & Comunidad Valenciana & 27 & ETA & CNP \\
\hline $1-3-1984$ & Pedro Ortíz de Urbina & Vitoria & Euskadi & 63 & ETA & CNP \\
\hline 2-4-1984 & Bernardo Pérez & Bilbao & Castilla La Mancha & 27 & ETA & CNP \\
\hline 6-4-1984 & José Ortíz & Galdakao & Comunidad Valenciana & 31 & ETA & CNP \\
\hline 21-4-1984 & Antonio Velasco & Bilbao & Castilla y León & 39 & ETA & GC \\
\hline $14-5-1984$ & Juan Flores & Fuenterrabía & Cataluña & 20 & CAA & FA \\
\hline $14-6-1984$ & Ángel Zapatero & San Sebastián & Castilla y León & 39 & ETA & GC \\
\hline 2-7-1984 & Alberto Aznar & Portugalete & Euskadi & 64 & ETA & FA \\
\hline 19-7-1984 & Antonio Torrón & Portugalete & Castilla y León & 55 & ETA & GC \\
\hline 28-9-1984 & Victoriano Collado & Elburgo & Extremadura & 21 & ETA & GC \\
\hline 28-9-1984 & José Luis Veiga & Elburgo & Euskadi & 40 & ETA & GC \\
\hline 28-9-1984 & Agustín David Pascual & Elburgo & Madrid & 23 & ETA & GC \\
\hline 23-11-1984 & $\begin{array}{l}\text { Mohamed Ahmed Abderrah- } \\
\text { man }\end{array}$ & Irún & Ceuta & 33 & ETA & CNP \\
\hline 7-12-1984 & Francisco Javier Fernández & Galdakao & La Rioja & 43 & ETA & FA \\
\hline 7-12-1984 & Juan Enríquez & Galdakao & Andalucía & 39 & ETA & FA \\
\hline $12-5-1985$ & Máximo Antonio García & San Sebastián & Navarra & 29 & ETA & CNP \\
\hline $16-5-1985$ & Luis Lorenzo Navarro & Basauri & Castilla y León & 26 & ETA & CNP \\
\hline 21-5-1985 & Francisco Rivas & San Sebastián & Castilla La Mancha & 50 & ETA & CNP \\
\hline 21-5-1985 & Máximo Díaz & San Sebastián & Castilla y León & 35 & ETA & CNP \\
\hline $26-5-1985$ & Moisés Cosme Herrero & Algorta & Castilla y León & 30 & ETA & CNP \\
\hline $12-6-1985$ & José Millarengo & Portugalete & Galicia & 42 & ETA & FA \\
\hline
\end{tabular}




\begin{tabular}{|c|c|c|c|c|c|c|}
\hline Fecha & Nombre & Lugar & Procedencia & Años & Autor & Cuerpo \\
\hline $18-6-1985$ & Eugenio Recio & Santurtzi & Castilla y León & 51 & ETA & GC \\
\hline 9-7-1985 & Antonio Jesús Trujillo & San Sebastián & Andalucía & 22 & ETA & GC \\
\hline 9-7-1985 & Juan Merino & San Sebastián & Asturias & 21 & ETA & GC \\
\hline 29-7-1985 & Agustín Ruíz & Vitoria & Euskadi & 43 & ETA & CNP \\
\hline 3-8-1985 & Fernando Amor & Aiala & Galicia & 25 & ETA & GC \\
\hline $4-8-1985$ & José Expósito & Elgóibar & Andalucía & 62 & ETA & GC \\
\hline 14-9-1985 & Félix Gallego & Vitoria & Cantabria & 36 & ETA & CNP \\
\hline 25-9-1985 & Isidoro Díez & Pasaia & Castilla y León & 39 & ETA & GC \\
\hline 25-9-1985 & José Manuel Ibarzábal & San Sebastián & Euskadi & 20 & ETA & FA \\
\hline 25-9-1985 & Rafael Melchor & San Sebastián & Andalucía & 26 & ETA & FA \\
\hline 26-9-1985 & José Herrero & Lasarte-Oria & Euskadi & 67 & ETA & GC \\
\hline $5-12-1985$ & Mario Manuel Leal & Arrasate-Mondragón & Asturias & 29 & ETA & GC \\
\hline 30-12-1985 & Alejandro Sáenz & Lasarte-Oria & La Rioja & 58 & ETA & GC \\
\hline 14-3-1986 & José Antonio Álvarez & San Sebastián & Castilla y León & 26 & ETA & CNP \\
\hline $20-5-1986$ & Manuel Fuentes & Arrigorriaga & Galicia & 39 & ETA & CNP \\
\hline 8-6-1986 & Antonio Ramos & Arrasate-Mondragón & Andalucía & 28 & ETA & GC \\
\hline 28-6-1986 & Francisco Muriel & Zarautz & Andalucía & 30 & ETA & GC \\
\hline 26-7-1986 & Ignacio Mateu & Aretxabaleta & Madrid & 27 & ETA & GC \\
\hline 26-7-1986 & Adrián González & Aretxabaleta & Castilla y León & 29 & ETA & GC \\
\hline 18-8-1986 & José María Picatoste & Legutio & Euskadi & 58 & ETA & FA \\
\hline 25-10-1986 & Rafael Garrido & San Sebastián & Aragón & 59 & ETA & FA \\
\hline 28-10-1986 & Julio César Sánchez & Bilbao & Castilla y León & 31 & ETA & CNP \\
\hline 24-12-1986 & José Antonio Peña & Oiartzun & Andalucía & 26 & ETA & GC \\
\hline 14-7-1987 & Antonio Ángel López & Oñati & Galicia & 32 & ETA & GC \\
\hline 14-7-1987 & Pedro Galnares & Oñati & Castilla y León & 26 & ETA & GC \\
\hline 6-8-1987 & Rafael Mucientes & Vitoria & Castilla y León & 37 & ETA & CNP \\
\hline 6-8-1987 & Antonio Ligero & Vitoria & Andalucía & 30 & ETA & CNP \\
\hline 8-9-1987 & Cristóbal Martín & Bilbao & Castilla y León & 51 & ETA & GC \\
\hline 9-9-1987 & Federico Carro & Gernika & Castilla y León & 29 & ETA & GC \\
\hline 9-9-1987 & Manuel Ávila & Gernika & Andalucía & 22 & ETA & GC \\
\hline 25-9-1987 & Vicente Montoya & Barakaldo & Euskadi & 42 & ETA & CNP \\
\hline 27-9-1987 & Wenceslao Maya & San Sebastián & Extremadura & 31 & ETA & CNP \\
\hline
\end{tabular}




\begin{tabular}{|c|c|c|c|c|c|c|}
\hline Fecha & Nombre & Lugar & Procedencia & Años & Autor & Cuerpo \\
\hline $1-11-1987$ & Antonio Mateo & Ordizia & Andalucía & 32 & ETA & GC \\
\hline 11-12-1987 & José Luis Gómez & Soraluze & Extremadura & 44 & ETA & GC \\
\hline 19-3-1987 & Pedro Ballesteros & Durango & Madrid & 24 & ETA & GC \\
\hline 27-3-1988 & Luis Azcárraga & Salvatierra & Euskadi & 81 & ETA & FA \\
\hline $15-4-1988$ & Francisco Espina & Vitoria & Andalucía & 30 & ETA & CNP \\
\hline $15-4-1988$ & Antonio Gómez & Vitoria & Andalucía & 33 & ETA & CNP \\
\hline 10-9-1988 & Martín Martínez & Izurtza & Castilla y León & 33 & ETA & CNP \\
\hline 10-9-1988 & Pedro Antonio Fonte & Izurtza & Galicia & 27 & ETA & CNP \\
\hline 29-10-1988 & Cristóbal Díaz & Bilbao & Andalucía & 36 & ETA & CNP \\
\hline 18-12-1988 & José Antonio Barrado & Éibar & Extremadura & 30 & ETA & CNP \\
\hline $12-4-1989$ & José Calvo & Getxo & Castilla y León & 51 & ETA & GC \\
\hline 25-4-1988 & Juan Bautista Castellanos & Bilbao & Extremadura & 56 & ETA & FA \\
\hline 24-5-1989 & José María Sánchez & Bilbao & Castilla y León & 34 & ETA & CNP \\
\hline $24-5-1989$ & Manuel Jódar & Bilbao & Andalucía & 35 & ETA & CNP \\
\hline 29-5-1989 & Juan Pedro González & Irún & Murcia & 34 & ETA & CNP \\
\hline 6-10-1989 & José Ángel Álvarez & San Sebastián & Castilla y León & 31 & ETA & CNP \\
\hline 6-11-1989 & Eladio Rodríguez & Bilbao & Galicia & 50 & ETA & CNP \\
\hline $30-1-1990$ & José Ignacio Pérez & Galdakao & Castilla y León & 39 & ETA & CNP \\
\hline $1-3-1990$ & Aureliano Rodríguez & San Sebastián & Andalucía & 65 & ETA & FA \\
\hline $4-4-1990$ & Benjamín Quintano & Pasaia & Castilla y León & 49 & ETA & GC \\
\hline 13-6-1990 & José Lasanta & San Sebastián & Cuba & 71 & ETA & FA \\
\hline 28-6-1990 & Ignacio Urrutia & San Sebastián & Euskadi & 74 & ETA & FA \\
\hline 2-9-1990 & José Manuel Alba & Bilbao & Aragón & 22 & ETA & GC \\
\hline 18-11-1990 & Daniel López & Santurtzi & Galicia & 41 & ETA & CNP \\
\hline 18-11-1990 & José Francisco Hernández & Santurtzi & Santa Cruz de Tenerife & 32 & ETA & CNP \\
\hline $14-12-1990$ & Luis Alfredo Achurra & Amorebieta & Euskadi & 37 & ETA & CNP \\
\hline 2-1-1991 & Luis García & San Sebastián & Aragón & 57 & ETA & FA \\
\hline 31-1-1991 & Francisco Díaz de Cerio & Bilbao & Euskadi & 41 & ETA & GC \\
\hline 16-3-1991 & Luis Aragó & San Sebastián & Aragón & 28 & ETA & GC \\
\hline 6-5-1991 & Francisco Robles & Pasaia & Andalucía & 21 & ETA & GC \\
\hline 9-5-1991 & Francisco Álvarez & Ortuella & Extremadura & 38 & ETA & GC \\
\hline 13-6-1991 & Ricardo Couso & Trápaga & Galicia & 38 & ETA & GC \\
\hline
\end{tabular}




\begin{tabular}{|c|c|c|c|c|c|c|}
\hline Fecha & Nombre & Lugar & Procedencia & Años & Autor & Cuerpo \\
\hline 28-7-1991 & Carlos Pérez & Getxo & Castilla y León & 22 & ETA & GC \\
\hline 23-10-1991 & Eduardo Sobrino & San Sebastián & Galicia & 34 & ETA & GC \\
\hline 23-10-1991 & Juan Carlos Trujillo & San Sebastián & Castilla La Mancha & 25 & ETA & GC \\
\hline 19-11-1991 & Pedro Carbonero & Galdakao & Extremadura & 54 & ETA & $\mathrm{GC}$ \\
\hline 14-1-1992 & José Anseán & Bilbao & Galicia & 38 & ETA & CNP \\
\hline 23-1-1992 & Juan Manuel Helices & Irún & Andalucía & 33 & ETA & CNP \\
\hline 17-8-1992 & José Manuel Fernández & Oiartzun & Andalucía & 25 & ETA & GC \\
\hline $17-8-1992$ & Juan Martínez & Oiartzun & Galicia & 23 & ETA & GC \\
\hline 14-9-1992 & Ricardo González & San Sebastián & Castilla y León & 38 & ETA & CNP \\
\hline 18-3-1993 & Emilio Castillo & San Sebastián & Castilla La Mancha & 31 & ETA & GC \\
\hline 16-9-1993 & Juvenal Villafañe & Andoain & Castilla y León & 78 & ETA & GC \\
\hline 4-4-1994 & Fernando Jiménez & Bilbao & Euskadi & 29 & ETA & GC \\
\hline 28-4-1994 & José Benigno Villalobos & Trápaga & Euskadi & 39 & ETA & GC \\
\hline 21-8-1994 & José Santana & Berango & Andalucía & 37 & ETA & CNP \\
\hline
\end{tabular}

Fuente: Elaboración propia sobre los datos obtenidos de López Romo (2015) y del Mapa del Terror de COVITE. 